\title{
Sensitivity of Hybrid ENSO Models to Unresolved Atmospheric Variability
}

\author{
J. Zavala-Garay,* C. Zhang, ${ }^{+}$A. M. Moore, ${ }^{*}$ A. T. Wittenberg, ${ }^{@}$ M. J. Harrison, ${ }^{@}$ A. Rosati, ${ }^{@}$ \\ JÉRÔME Vialard, \& AND R. KLEEMAN** \\ *Institute of Marine and Coastal Sciences, Rutgers, The State University of New Jersey, New Brunswick, New Jersey \\ + Rosenstiel School of Marine and Atmospheric Science, University of Miami, Miami, Florida \\ \# University of California, Santa Cruz, Santa Cruz, California \\ @ GFDL, Princeton University, Princeton, New Jersey \\ \& LODYC, Unité Mixte de Recherche CNRS, Université Paris, Paris, France \\ **Courant Institute of Mathematical Sciences, New York University, New York, New York
}

(Manuscript received 2 November 2005, in final form 9 October 2007)

\begin{abstract}
A common practice in the design of forecast models for ENSO is to couple ocean general circulation models to simple atmospheric models. Therefore, by construction these models (known as hybrid ENSO models) do not resolve various kinds of atmospheric variability [e.g., the Madden-Julian oscillation (MJO) and westerly wind bursts] that are often regarded as "unwanted noise." In this work the sensitivity of three hybrid ENSO models to this unresolved atmospheric variability is studied. The hybrid coupled models were tuned to be asymptotically stable and the magnitude, and spatial and temporal structure of the unresolved variability was extracted from observations. The results suggest that this neglected variability can add an important piece of realism and forecast skill to the hybrid models. The models were found to respond linearly to the low-frequency part of the neglected atmospheric variability, in agreement with previous findings with intermediate models. While the wind anomalies associated with the MJO typically explain a small fraction of the unresolved variability, a large fraction of the interannual variability can be excited by this forcing. A large correlation was found between interannual anomalies of Kelvin waves forced by the intraseasonal MJO and the Kelvin waves forced by the low-frequency part of the MJO. That is, in years when the MJO tends to be more active it also produces a larger low-frequency contribution, which can then resonate with the large-scale coupled system. Other kinds of atmospheric variability not related to the MJO can also produce interannual anomalies in the hybrid models. However, when projected on the characteristics of Kelvin waves, no clear correlation between its low-frequency content and its intraseasonal activity was found. This suggests that understanding the mechanisms by which the intraseasonal MJO interacts with the ocean to modulate its low-frequency content may help to better to predict ENSO variability.
\end{abstract}

\section{Introduction}

El Niño-Southern Oscillation (ENSO) irregularity has been postulated to result from low-order chaos of nonlinear resonances of the ENSO mode with the annual cycle (e.g., Jin et al. 1994; Tziperman et al. 1994; Chang et al. 1995), to result from the modulation by small changes in the background state (An and Wang 2000; Fedorov and Philander 2000; Wittenberg 2002), or to result from the sporadic forcing of intraseasonal variability on the ENSO mode (e.g., Lau 1985; Penland

Corresponding author address: J. Zavala-Garay, IMCS, Rutgers, The State University of New Jersey, 71 Dudley Rd., New Brunswick, NJ 08901-8521.

E-mail: jzavala@marine.rutgers.edu and Sardeshmukh, 1995; Blanke et al. 1997; Eckert and Latif 1997; Moore and Kleeman 1999a; Penland et al. 2000; Thompson and Battisti 2000; Fedorov 2002; Zavala-Garay et al. 2003). The last possibility has gained more research attention in the past decade after several strong intraseasonal events have been observed prior to ENSO warming to influence predictions by coupled models (e.g., Fedorov et al. 2003; Lengaigne et al. 2003; McPhaden 2004). In fact, the state of the intraseasonal variability in the tropical Pacific and its effects on the ocean are now documented by some agencies as part of their diagnostics (see, e.g., the ENSO diagnostic discussion issued by the Climate Prediction Center available online at http://www.cpc.ncep.noaa. gov/products).

This observational evidence suggests that the as- 
sumed separation of scales on which a number of ENSO models are based should be revised. Of course these models are extremely useful in terms of shortterm seasonal prediction as most of the deterministic aspects of ENSO are contained in these models. They however cannot be used to understand the spread (or uncertainty) of the forecasts or the long-term evolution of ENSO if intraseasonal variability turns out to be important. In theory this kind of variability and its interactions with the ENSO should be reproduced by the coupled models containing atmospheric general circulation models (AGCMs). However, detailed evaluations of AGCMs suggest that many of them do not produce much intraseasonal variability at all and, if they do, the spatial distribution, phase, and seasonal cycle of this variability is usually unrealistic (Zhang et al. 2006). Given the observed influence of this kind of variability on the slowly evolving coupled system, one could expect these errors to propagate to other time scales in fully coupled GCMs.

In this work we will take an alternative approach to the fully coupled GCMs. We couple two state-of-theart ocean GCMs to simple atmospheric models that are able to generate basic large-scale wind feedbacks for ENSO growth and then externally impose the unresolved variability (UV) from observations. This procedure will allow us to carefully study the way the UV affects the slowly evolving coupled system in a more realistic framework. These so-called stochastic models are the natural extension of Hasselmann's climate paradigm (Hasselmann 1976) applied to the ENSO system [for a review of this approximation see Penland (1996)]. We define the UV as that part of the atmospheric variability that is not linearly related to the ocean circulation. The term "stochastic" here simply refers to processes that "decorrelate very fast" on ENSO time scales. These processes can have (and in fact they do) spatial coherence and populate all frequencies (e.g., a spatially coherent red noise process). It should be noted however that, while in these models the stochastic forcing (SF) is allowed to influence ENSO, the possible influence of the ENSO mode on the SF is not included. Using the terminology of stochastic differential equations (SDEs), we treat the UV as an additive SF acting on the slowly evolving ENSO system. Clearly understanding such model will be of benefit to understanding the more general case where the UV is allowed to be modified by the ENSO system, formally referred to as multiplicative SF. Such state-dependent SF has the potential to fundamentally alter the probability density functions of coupled models (e.g., Perez et al. 2005; Jin et al. 2007).

It should be noted that the use of stochastic models does not necessarily contradict the validity of chaotic models. Stochastic models are often derived as tools that can approximate the statistics of chaotic systems [for a discussion of this issue see Leith 1996; Penland 2003)]. In view of the deficiencies of the AGCMs in modeling the SF, the great utility of such a simplification in the present work is that the external forcing is prescribed from observations and therefore is expected to add an important piece of realism to the hybrid models. In addition, this approach will allow us to evaluate the impact of the different sources of the stochastic forcing in an objective way, a task that would be very difficult using coupled GCMs.

The Madden-Julian oscillation (MJO) (Madden and Julian 1971) has been postulated to be an important source of SF (Mantua and Battisti 1995; Moore and Kleeman 1999b; Zavala-Garay et al. 2005, hereafter ZG05). In fact, MJO activity in the western Pacific has been shown to lead ENSO by several months (Zhang and Gottschalck 2002; Hendon et al. 2007). However, the numerical investigations of this hypothesis have been done using very simple ocean models (Batstone and Hendon 2005), coupled models of intermediate complexity (Zavala-Garay et al. 2003; ZG05), or using an idealized MJO forcing acting on a stand-alone ocean GCM (Kessler and Kleeman 2000). Intermediate models are often criticized for their simplicity because several processes are highly parameterized (e.g., vertical mixing) or even not represented (e.g., tropical instability waves). Therefore it is important to ascertain whether the conclusions drawn from these studies are robust in dynamical systems that consider all these processes. In this work we advance these studies by documenting responses to the MJO and other sources of SF by standalone ocean GCMs and their hybrid versions coupled to statistical atmospheric models.

The rest of this work is organized as follows. In section 2 we describe the hybrid models used in this study. The way that we estimate the SF from observations and the contributions of the MJO and other sources of variability to the stress perturbations are described in section 3. To better understand the coupled model experiments, in section 4 we first study the response of the ocean to the SF perturbations. The response of the hybrid coupled models is then presented in section 5. Finally a summary is presented in section 6 .

\section{Models}

The hybrid models used in this study consist of three different simple atmospheric models coupled to two ocean GCMs (OGCMs). The two OGCMs are the Océan Parallélisé (OPA) 8.1 (Madec et al. 1998) ocean 
model of the Laboratoire d'Océanographie Dynamique et de Climatologie (LODYC) and the Geophysical Fluid Dynamics Laboratory (GFDL) Modular Ocean Model version 4 (MOM4; Griffies at al. 2003) configured for the tropics.

\section{a. OPA OGCM}

The version of the model used here is configured for the tropical Pacific and is described in Vialard et al. (2001). Temperature is gradually damped toward Levitus (1982) climatology at latitudes higher than $20^{\circ}$. The model has a $1^{\circ}$ zonal resolution and a meridional resolution varying from $0.5^{\circ}$ at the equator to $2^{\circ}$ at the meridional boundaries $\left(30^{\circ} \mathrm{S}-30^{\circ} \mathrm{N}\right)$. There are 25 levels in the vertical with maximum resolution of $10 \mathrm{~m}$ in the top $150 \mathrm{~m}$. A realistic coastal geometry and bathymetry is considered even though the model is closed in the western boundary (i.e., no Indonesian Throughflow). A turbulent closure hypothesis is used to parameterize the unresolved subgrid-scale physics. Lateral mixing is affected by a second-order operator with constant eddy viscosity and diffusivity coefficients. Vertical mixing coefficients are determined from a prognostic equation for turbulent kinetic energy and from a diagnosed turbulent length scale (Maes et al. 1998).

Details about the initialization process can be found in Moore et al. (2003). After the spinup period, the model was forced with the monthly Florida State University (FSU) wind stress anomalies for the period January 1960-December 1978. The OPA model integrations presented in this study use the final state of this period of integration as the initial condition.

The sea surface temperature (SST) is relaxed toward the observed mean seasonal cycle of SST derived from the Reynolds and Smith (1994) analysis using a relaxation coefficient of $40 \mathrm{~W} \mathrm{~m}^{-2}{ }^{\circ} \mathrm{C}^{-1}$. This might imply a too strong damping in the eastern Pacific but it produces a more realistic climatology (Vialard et al. 2001) Similarly, the salinity is forced by an annual-mean net freshwater flux derived from 15-yr European Centre for Medium-Range Weather Forecasts (ECMWF) ReAnalysis (ERA-15) net evaporation minus precipitation and relaxed toward the annual mean sea surface salinity (SSS) of Levitus (1982).

\section{b. MOM4 OGCM}

Although this model is global, a gradual damping toward Levitus and Boyer (1994) climatology is applied poleward of $45^{\circ}$. The model has a $2^{\circ}$ zonal resolution and a meridional resolution varying from $0.5^{\circ}$ at the equator to $5^{\circ}$ near the Poles. Indonesian Throughflow is allowed. There are 25 vertical levels with a maximum resolution of $15 \mathrm{~m}$ in the top $150 \mathrm{~m}$.
Details about the spinup/flux adjustment methodology are described in Zhang et al. (2005). In coupled mode, a "climatological flux-adjustment term" is prescribed (see Zhang et al. 2005), and the SST and SSS damped toward climatology with an $e$-folding time of 100 days. This procedure allows the model to maintain a realistic climatology without strongly damping the interannual anomalies.

All the MOM4 OGCM integrations presented in this work start from January of 1979. This initial condition was obtained by nudging the coupled model (see section 2c) toward observed SST and imposing an estimate of the SF from the 40-yr ECMWF Re-Analysis (ERA-40).

\section{c. Hybrid models}

The two OGCMs were coupled to simple atmospheric models that are capable of producing basic large-scale feedbacks for ENSO growth. We refer to such simple atmospheric models as A1, A2, and A3. The resulting hybrid models along with its atmospheric components are summarized next.

\section{1) $\mathrm{OPA}+\mathrm{A} 1$ HYBRID MODEL}

The OPA model was coupled to a statistical atmospheric model derived from singular value decomposition (SVD) analysis (Bretherton et al. 1992) between the monthly FSU wind stress anomalies and the simulated SST anomalies from 1960 to 2000. Two SST singular vectors, dominating the large-scale covariance of the modeled SST with the applied stress, are considered as predictors. The dynamical properties of this coupled model are discussed in Moore et al. (2003, 2006). For the strength of the coupling coefficient chosen the model exhibits a stable oscillation with an $e$-folding time of about $2.5 \mathrm{yr}$. The computed stress anomalies were modified every day by adding the externally imposed SF (in the form of wind stress) and the resulting field used to force the ocean.

\section{2) $\mathrm{OPA}+\mathrm{A} 2$ HYBRID MODEL}

The OPA model was also coupled with the simple dynamical atmospheric model described by Kleeman (1991). It is a steady, two pressure level (250 and 750 $\mathrm{mb})$ Gill-type model linearized about a state of rest in an equatorial $\beta$ plane with a first baroclinic mode phase speed of $60 \mathrm{~m} \mathrm{~s}^{-1}$, a damping Rayleigh friction, and Newtonian cooling of 3 days. The heating used to drive the atmosphere is partitioned into latent heating and direct thermal heating. The former, dominating in the western Pacific, is an important source of nonlinearity 
in the form of a threshold. Latent heat release by deep penetrative convection is allowed when the moist static energy of air parcels exceeds a critical value corresponding to an SST of about $28^{\circ} \mathrm{C}$. The model has been shown to give a reasonable distribution of precipitation and circulation anomalies of several observed warm and cold phases of ENSO (Kleeman 1991). In coupled mode, the SST anomalies computed from the OPA OGCM were passed to the A2 model every time step to determine the coupled wind anomalies $\left(u_{c}\right)$. These wind anomalies were then converted to pseudostress using $\tau \approx 2|\bar{u}| u_{c}$, where $\bar{u}$ is the FSU-based zonal wind climatology. This relation results from direct linearization of the stress perturbations produced by the coupled wind and was found to be an excellent approximation. The SF is then added to this coupled contribution every day and the resulting field used to force the ocean.

\section{3) MOM4 + A3 HYBRID MODEL}

The MOM4 ocean model was coupled to a statistical atmosphere derived from the National Centers for Environmental Prediction version 2 (NCEP2) reanalysis. The use of another statistical atmosphere is motivated by the fact that the behavior of hybrid models strongly depends on which atmospheric product is used in its design (Harrison et al. 2002). The statistical atmosphere used in this hybrid model is based on a direct linear regression of the NCEP2 stress anomalies onto the leading (first seven modes) SST singular vectors of the SST-stress covariance as in Wittenberg (2002) and Harrison et al. (2002). A detailed description of this statistical atmosphere can be found in Wittenberg (2002, his chapter 3).The computed stress anomalies were then modified by adding the externally imposed SF and then used to force the ocean.

\section{Stochastic forcing}

To study the response of the hybrid models to the unresolved variability we need to remove first from the observed wind anomalies the part that is associated with the large-scale coupled system. One way of doing so is to directly high pass the observed wind stress anomalies. This procedure is useful to study the possible rectification of high frequency forcing onto the slow coupled ENSO system. It is not useful however to study the possible linear amplification of the perturbations induced by the UV (e.g., see ZG05). Therefore, an alternative approach of filtering out the ENSO signal statistically is used. Similar filters have been used previously as a means of deriving the statistical structure of the UV (e.g., Blanke et al. 1997; Roulston and
Neelin 2000; Wittenberg 2002; Zavala-Garay et al. 2004) or as a means of filtering out the ENSO signal to construct near-real-time indices of the MJO (Wheeler and Hendon 2004).

A strong limitation of this method is the implied assumption of strong linearity in the SST-wind stress relationship, which is known not to hold all the time (e.g., Vecchi et al. 2006). However, these models have been shown to reproduce most of the interannual anomalies of the wind associated with ENSO, and most of the hybrid models used to date have a similar statistical relationship in its atmospheric component. Therefore, defining the residual of this regression as the UV is consistent with the fact that this is the variability not reproduced by these hybrid models.

In this study we use the NCEP-Department of Energy (DOE) Atmospheric Model Intercomparison Project (AMIP-II) NCEP2 reanalysis as a proxy of the observed atmospheric variability. The NCEP2 reanalysis is an updated version of the NCEP-National Center for Atmospheric Research (NCEP-NCAR) reanalysis that eliminates several human processing errors and features improved physics (Kanamitsu et al. 2002). There are considerable differences in the zonal wind stress between NCEP-NCAR and NCEP2 reanalyses, with the latter stronger and more variable over the central Pacific (see Fig. 1 of Wittenberg 2004).

The linear, large-scale ENSO signal dependent on tropical Pacific SST was removed from the 10-m zonal wind of the NCEP2 reanalysis by multivariate linear regression with the SST analysis of Reynolds and Smith (1994). The domains considered were the equatorial strip $\left(15^{\circ} \mathrm{S}-15^{\circ} \mathrm{N}\right)$ for the zonal wind and the tropical Pacific $\left(20^{\circ} \mathrm{S}-20^{\circ} \mathrm{N}, 112^{\circ} \mathrm{E}-85^{\circ} \mathrm{W}\right)$ for the SST. A semiglobal scale is used for the zonal wind in order to objectively isolate the MJO from the residual field. The SST was linearly interpolated to daily values for compatibility with the zonal wind data. A climatology was computed for the period considered (January 1979December 2003) and stabilized with a 91-day running mean (Madden and Jones 2001). The zonal wind anomalies $\left(u_{a}\right)$ recovered after removal of this climatology still exhibited a small amount of energy concentrated around the first two harmonics of the annual cycle (especially in the eastern Pacific). Therefore, the first three harmonics were also removed. The singular value decomposition between the wind and SST anomalies gave two statistically significant modes (North et al. 1982) explaining $85 \%$ of the total squared covariance. The time history of the projection of the corresponding two SST modes was then used as predictors for the zonal wind. The resulting SST-forced empirical model reproduces most of the interannual vari- 
ability of the observations (see Fig. 1 of ZG05) and this is roughly the variability modeled by hybrid models with statistical atmospheres.

The resulting residual was further separated as a part due to the MJO plus another part not related to the MJO. The MJO was determined via Hilbert singular value decomposition (HSVD) of the residual. Prior to the HSVD, a space filter is applied to emphasize the large scale of the MJO resulting in an effective resolution of $10^{\circ}$ and $5^{\circ}$ in the zonal and meridional directions, respectively. This method has been shown to efficiently isolate the propagating component of the MJO (Zhang and Hendon 1997) as well as its low-frequency variability (ZG05). The MJO estimate was based on three Hilbert singular vectors, as described in ZG05. The non-MJO contribution is then defined as the difference between the residual zonal wind and the MJO estimate.

To illustrate the different separations performed on the zonal wind anomaly, Fig. 1 shows a nonparametric estimate of the probability density function (PDF) of the different components of the equatorial zonal wind $\left(5^{\circ} \mathrm{S}-5^{\circ} \mathrm{N}\right.$ average). The nonparametric PDFs are obtained using a Gaussian kernel < density estimator (Rosenblatt 1956) with an optimal bandwidth

$$
h=2\left(\frac{4}{3 n}\right)^{1 / 5} \sigma
$$

where $\sigma$ is the standard deviation based on $n$ data points (Silverman 1986). Figure 1a shows the PDF of the zonal wind linearly related to SST as a function of longitude. This part of the zonal wind shows some differences between El Niño and La Niña phases, with the westerly wind anomalies during El Niño phase more confined to the central/eastern Pacific than the easterly wind anomalies during La Niña phase. As an example, Fig. 1a also shows a snapshot of the wind anomalies during the 1997-98 El Niño phase (black solid line) and 1998-99 La Niña phase (black dashed line). This difference between the El Niño and La Niña phase produces asymmetric PDFs at some longitudes. We tested the fitted PDFs against the null hypothesis that the data were drawn from a Gaussian distribution having the same variance using the Kolmogorov-Smirnov (K-S) statistics (Wilks 1995). The K-S test looks for the largest difference in magnitude $\left(D_{n}\right)$ between the empirical and theoretical (Gaussian) cumulative distribution functions (CDFs), which should exceed the value 0.886 / $\sqrt{n}$ for the null hypothesis to be rejected at the $5 \%$ level. Using $n=4 \times 25$ (number of seasons) as the number of independent observations, the null hypothesis can be rejected at the longitudes marked with as-
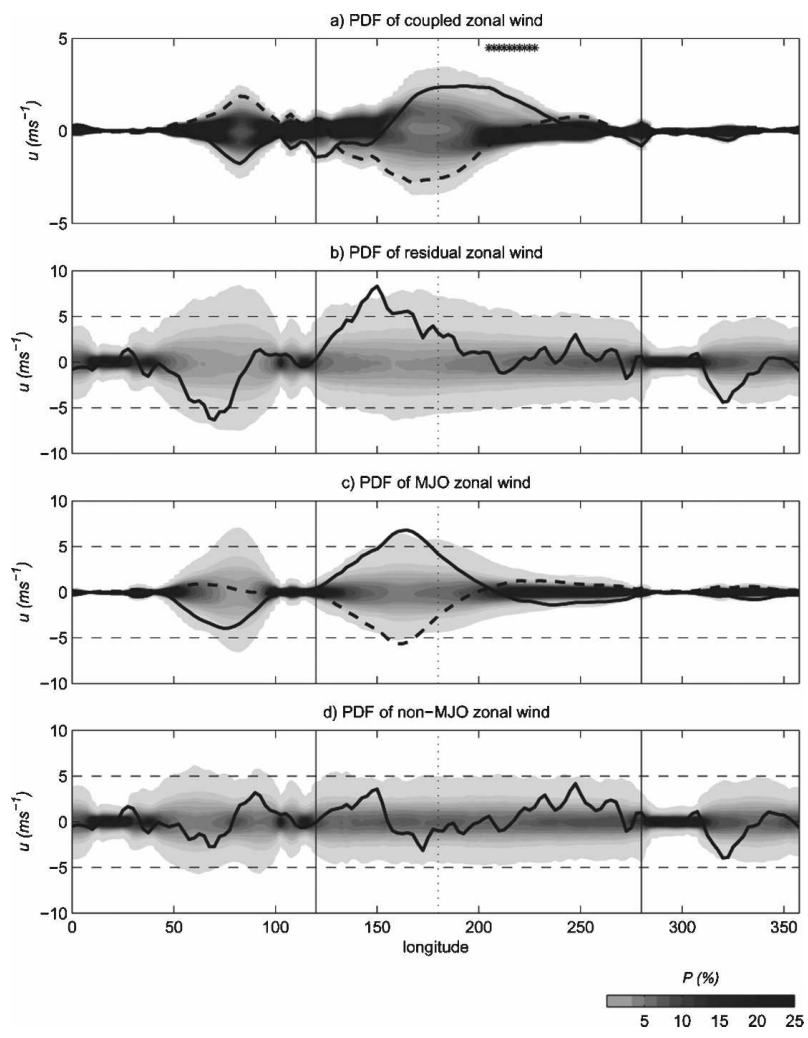

FIG. 1. Nonparametric PDFs of equatorial $\left(5^{\circ} \mathrm{N}-5^{\circ} \mathrm{S}\right.$ average) zonal wind anomaly as a function of longitude: (a) component linearly related to SST, (b) residual, (c) MJO component of the residual, and (d) nonMJO component of the residual. In (a) the asterisks indicate the longitudes where the estimated PDFs significantly deviate from a Gaussian distribution at the 5\% level according to the $\mathrm{K}-\mathrm{S} D_{n}$ statistics. Snapshots of the coupled zonal wind during El Niño (solid black line corresponding to 1 Jan 1998) and La Niña (dashed black line corresponding to 1 Jan 1999) are also shown. Similarly, in (b), (c) snapshots of the corresponding wind components are shown for 10 Mar 1997. For comparison, the dashed line in (c) shows the MJO wind during a strong easterly phase. The shading scale shows the probability $P(u-\Delta u / 2 \leq u \leq u+\Delta u / 2)$ for $\Delta u=0.5 \mathrm{~m} \mathrm{~s}^{-1}$.

terisks in Fig. 1a. That is the deviations $D_{n}$ at these longitudes are larger than what could be expected to be obtained when estimating a PDF from $n$ samples drawn from a Gaussian distribution.

The strongest zonal wind anomalies are associated with the residual wind as illustrated by its PDF in Fig. 1b. Though rare (i.e., low probability), the residual can exhibit zonal wind anomalies as large as $10 \mathrm{~m} \mathrm{~s}^{-1}$ in the western Pacific and eastern Indian Ocean. As a reference a snapshot of the strong intraseasonal event of March of 1997 is also shown in Fig. 1b (black line). This event is thought to have significantly influenced the evolution of the 1997-98 El Niño (McPhaden 1999; van Oldenborgh 2000; Vialard et al. 2001). Vecchi et al. (2006) found that a fraction of this wind anomaly could 
have been the result of a nonlinear response to SST, and therefore not reproducible by linear statistical atmosphere models such as those used in this study.

Assuming a typical decorrelation time of 10 days we applied the K-S test to the fitted PDFs in Fig. 1b using $n=36 \times 25$ and found that the null hypothesis (the residual comes from a Gaussian distribution) cannot be rejected at the $5 \%$ significance level. It should be noted however that, because $D_{n}$ is the absolute value of the largest difference between the theoretical and empirical $\mathrm{CDFs}$, the $\mathrm{K}-\mathrm{S}$ statistics is a one-sided test. Therefore, large values of $D_{n}$ will indicate large discrepancies that are unfavorable to the null hypothesis. For Fig. 1b the largest values of $D_{n}$ were found around the warm pool edge, suggesting some deviations from Gaussianity and in agreement with the view that part of the wind in this area is due to nonlinear processes. However the departures from Gaussianity cannot be backed up with the data and analysis tools used here.

We also note that the "residual" wind anomalies shown over the Indian Ocean (Fig. 1b) could have a "coupled" component that is responding to the Indian Ocean SSTs, which are not considered in our regression. However, a large fraction of these wind anomalies can be associated with the eastward-propagating component of the MJO as shown in Fig. 1c. A drastic decrease in variance is observed around the Maritime Continent (from $2.4 \mathrm{~m} \mathrm{~s}^{-1}$ at $82.5^{\circ} \mathrm{E}$ to about $0.3 \mathrm{~m} \mathrm{~s}^{-1}$ at $100^{\circ}-120^{\circ} \mathrm{E}$ ), as reported in previous studies (e.g., Zhang and Hendon 1997). Larger MJO variability at these longitudes (not shown) was observed north and south of $5^{\circ}$ latitude. Figure $1 \mathrm{c}$ also shows that part of the residual shown in Fig. $1 \mathrm{~b}$ that can be associated with the MJO (black line). Also included is the MJO component for a strong easterly phase as an example. Even though the MJO is sometimes associated with small wind anomalies, its large zonal extent makes it a very efficient source of stochastic forcing for some ENSO models (ZG05). Wind anomalies associated with other high frequency events (e.g., Yu and Rienecker 1998; Hartten 1996; Harrison and Vecchi 1997) are associated with smaller scales. These events are contained in our non-MJO estimate and its PDF is shown in Fig. 1d. In contrast with the MJO, the non-MJO is evenly distributed over the equatorial Pacific and exhibits smaller spatial decorrelation scales. As an example we also show in Fig. 1d the non-MJO contribution for the residual wind shown in Fig. 1 b.

The perturbations in stress due to the UV or residual wind are proportional to

$$
\tau_{n}=\tau\left(\bar{u}+u_{c}+u_{n}\right)-\tau\left(\bar{u}+u_{c}\right),
$$

where $\tau(u)=|u| u$ is the pseudostress, $\bar{u}$ is the zonal wind seasonal climatology, $u_{c}$ is the part linearly correlated with the SST, and $u_{n}=u_{a}-u_{c}$ is the residual. Similarly, the stress perturbation due to the presence of the MJO is given by $\tau_{\mathrm{MJO}}=\tau\left(\bar{u}+u_{c}+u_{\mathrm{MJO}}\right)-$ $\tau\left(\bar{u}+u_{c}\right)$, where $u_{\mathrm{MJO}}$ is that part of the residual $u_{n}$ that is associated with the MJO. A similar stress perturbation can be defined for other sources of residual wind not associated with the MJO using $u_{\text {nonMJO }}=u_{n}$ $u_{\mathrm{MJO}}$ (the alternative definition $\tau_{\text {nonMJO }}=\tau_{n}-\tau_{\mathrm{MJO}}$ gave similar results). The use of these definitions was motivated by the fact that the stochastic stress perturbations depend on the background wind $\left(\bar{u}+u_{c}\right)$ over which they develop. Therefore, strictly speaking, the residual $u_{n}$ should be included as a multiplicative stress perturbation in the hybrid models since its amplitude depends on $u_{c}$ or SST. This is only possible for model $\mathrm{OPA}+\mathrm{A} 2$ whose atmospheric component solves for the zonal wind and not for the zonal stress. Experiments performed with this model for multiplicative noise gave very similar results to the case where the noise was regarded as additive. The reason of this result is that the stress perturbations (and therefore the model responses) were found to be well approximated by $\tau_{n} \approx$ $2\left|\bar{u}+u_{c}\right| u_{n} \approx 2|\bar{u}| u_{n}$. This last relation also give us a direct way of transforming wind anomalies to stress anomalies.

\section{Ocean stand-alone response}

We do not consider meridional wind anomalies in our analysis. The reason for this approximation was that the meridional wind component of the MJO is very weak (Zhang 1996) and that most of the large-scale SST variability can be still be recovered by the OGCMs when this component of the wind is not considered, as shown next. Figure 2 compares the observed SSTA along the equator $\left(5^{\circ} \mathrm{S}-5^{\circ} \mathrm{N}\right)$ with that modeled by the MOM4 and OPA OGCMs when the observed wind stress anomalies based on the zonal wind alone are imposed. The SST perturbations modeled by OPA (zonal mean $\mathrm{rms}=0.53^{\circ} \mathrm{C}$ ) are weaker than both the observations (zonal mean rms $=0.71^{\circ} \mathrm{C}$ ) and those modeled by MOM4 (zonal mean rms $=0.79^{\circ} \mathrm{C}$ ). This is a consequence of the strong relaxation term used in OPA as discussed before (see section 2a). Conceding this limitation, both OGCMs are capable of reproducing most of the observed large-scale interannual variations in SST when the correct zonal wind forcing is imposed.

To fully appreciate the response of the coupled hybrid models it is illustrative to first study the response of the ocean to the residual wind. The coherent part of the response of the ocean can be adequately charac- 


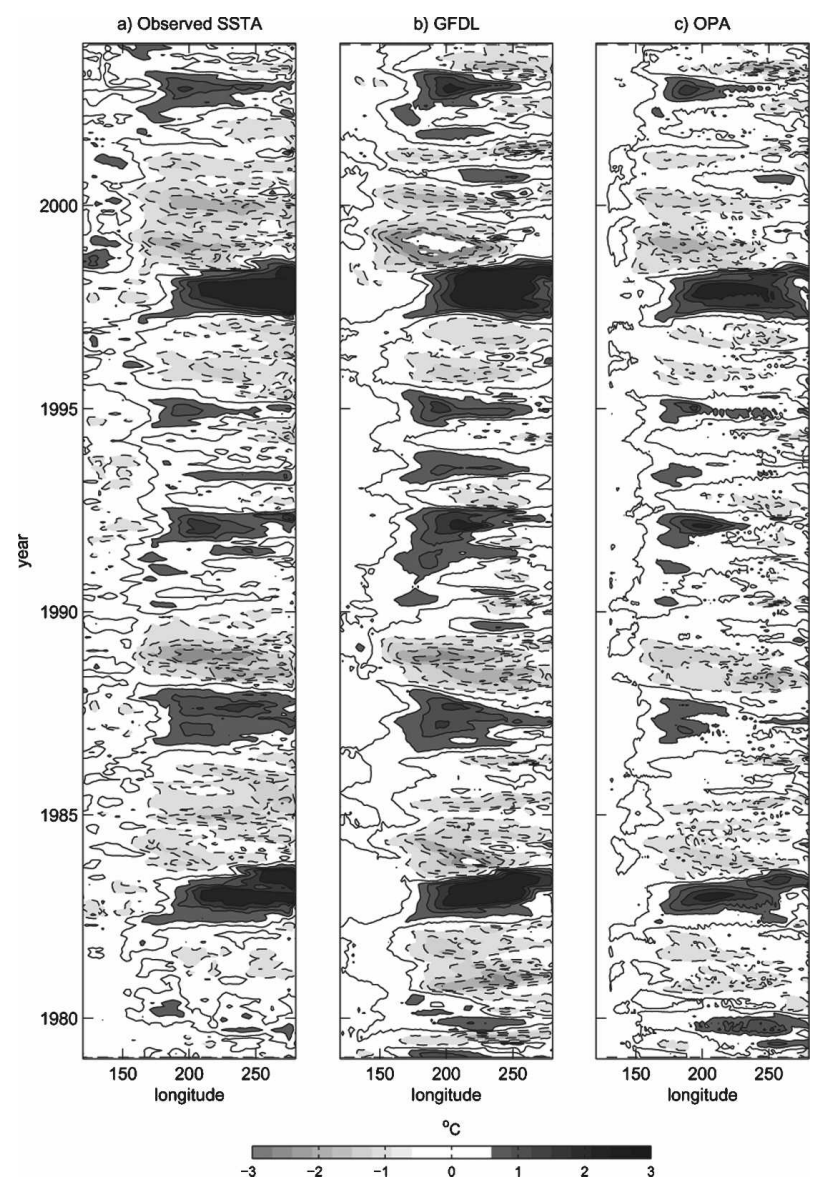

FIG. 2. SST anomalies along the equator $\left(5^{\circ} \mathrm{N}-5^{\circ} \mathrm{S}\right.$ average) (a) observed, (b) modeled by the MOM4 OGCM, and (c) modeled by the OPA OGCM: The OGCMs were forced by NCEP2 wind stress anomalies based on zonal wind alone.

terized by extended empirical orthogonal functions (EEOFs) (Weare and Nasstrom 1982) of the temperature field. In EEOF eigenanalysis is performed on the covariance of the analyzed state vector at different lags of interest. We use as the state vector the monthly mean temperature anomalies at different depths along the equator and the monthly mean SST anomalies. Monthly lags from 0 to 3 are considered. For computational reasons the model grid resolution was reduced by box averaging in all three spatial directions.

As discussed in the previous section, the MJO is associated with eastward-propagating large-scale coherent patterns while the non-MJO estimate is more irregular (both spatially and temporally; see Figs. 1c and $1 d)$. For this reason the most coherent part of the response of the ocean to the residual wind comes from the MJO. In this example we consider the OPA model response to the MJO estimate to illustrate the main aspects of the ocean response to UV. These aspects, however, are also observed when the model is forced with the full residual; they are, however, easily separated by the EEOF analysis of the response to the MJO. When the model was forced with the non-MJO estimate these modes are also found but they do not significantly stand out from other modes.

Three modes were found to be unambiguously determined by the record according to the criterion of North et al. (1982). The second mode (EEOF2) is in close quadrature with the first and is shown in Fig. 3. The first mode (EEOF1) describes the same phenomena as EEOF2 with the patterns shifted by 1 month. That is, the patterns of EEOF1 at lags $0,1,2$, and 3 months correspond to the patterns of EEOF2 at lags 3, 0,1, and 2 months in Fig. 3. This is also evident in the fact that they explain the same amount of variance (22\% each) and their principal components are highly correlated $(r=0.9)$ at 1-month lag. This pattern (Fig. 3) represents the response of the ocean to the westerly and easterly phases of the MJO. At zero lag the mode shows a nearsurface warming in the eastern Pacific produced by the arrival of a downwelling Kelvin wave. The signal is also apparent in the SST anomaly field. At the same time, a small negative subsurface temperature anomaly forced by the easterly phase of the MJO is also apparent in the western Pacific. At 1-month lag the eastern Pacific surface warming has decreased as the cooling propagates eastward along the thermocline (indicated by the thick black line). Lags 3 and 4 months show the surfacing and decaying of this cooling trend. Similarly, the first mode (not shown) describes the origin and eastward propagation of a warming trend over an anomalously cold eastern Pacific. These stochastically induced Kelvin waves can interact with the atmosphere once they manifest themselves in the SST field. This occurs mostly in the eastern Pacific. However, the alternate effect of the downwelling/upwelling signals produces coupled wind anomalies of opposite sign that tend to cancel out any growing SST (ZG05).

The MJO can effectively influence ENSO when the westerly phase dominates over the easterly phase. This process is captured in the third EEOF and is shown in Fig. 4. The field at zero lag is very similar to that of the EEOF2 with a near-surface warming located at the eastern Pacific (cf. Figs. 3a,b with 4a,b). However, in this mode the cooling trend associated with the easterly phase of the MJO is replaced by a warming trend resulting from an additional westerly phase of the MJO. The effect of the arrival of this additional warming trend to the eastern Pacific is to persist the small positive SST anomalies there. It should be noted, however, that this sequence of processes is not special to the MJO and that other sources of UV can also help to 


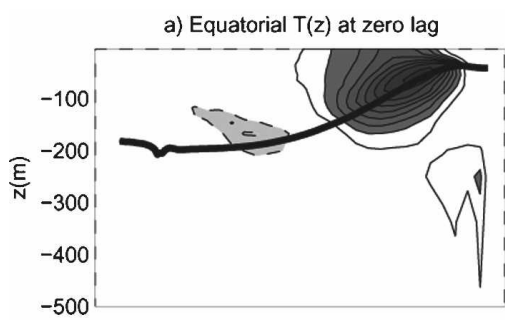

EEOF2

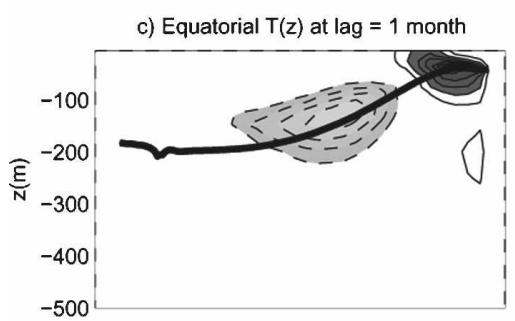

e) Equatorial $T(z)$ at lag $=2$ months

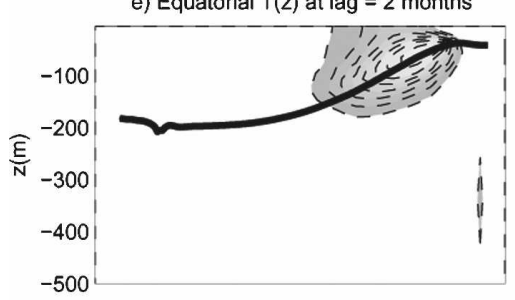

g) Equatorial $T(z)$ at lag $=3$ months

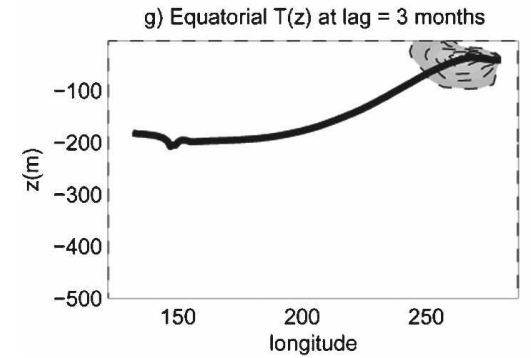

b) SSTA at zero lag

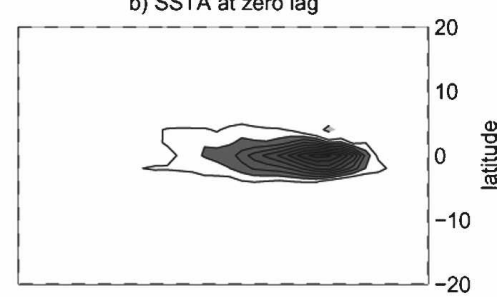

d) SSTA at lag = 1 month

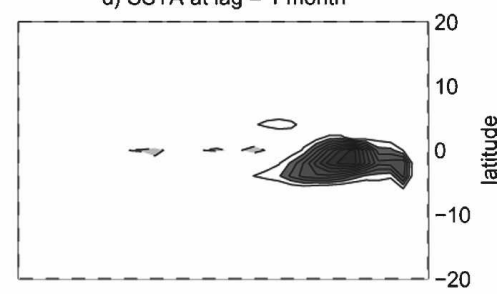

f) SSTA at lag $=2$ months

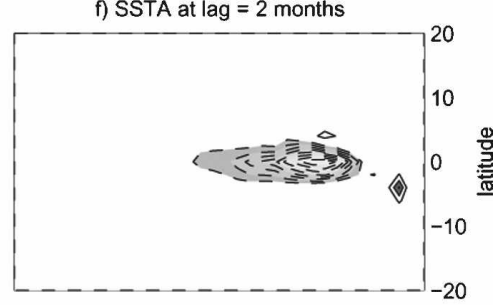

h) SSTA at lag $=3$ months

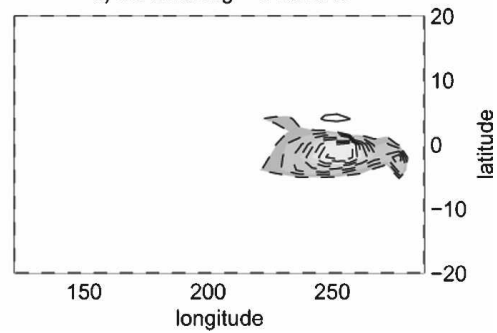

FIG. 3. Extended EOF mode 2 of the temperature field from the OPA OGCM forced by the MJO component of stochastic forcing (see text): (a), (c), (e), (g) Vertical cross sections in which the depth of the thermocline is represented by the annual mean $20^{\circ} \mathrm{C}$ isotherm (black solid line); (b), (d), (f), (h) SST anomaly. The amplitude of the anomalies is arbitrary with positive (negative) values dark (light) shaded.

maintain or modify SST anomalies in the eastern Pacific. However, the EEOF analysis suggests that the MJO plays an important role in this regard. While this ocean stand-alone scenario is important because it allow us to isolate the direct response of the ocean to the residual wind, it is unrealistic in the sense that, without coupling, atmospheric feedbacks are not included. This issue is addressed next.

\section{Coupled response}

Figure 5 shows the SST anomalies produced by the three hybrid coupled models when $\tau_{n}$ is imposed as an external forcing. All three models are capable of producing ENSO events at irregular intervals. It should be recalled that these models have been tuned to produce a damped oscillation. Therefore the observed interannual variability is maintained by the externally imposed residual in zonal stress. However, the occurrence of several ENSO events is not corroborated by the observations, especially in the 1985-90 interval (cf. Fig. 2). The zonally averaged correlation between the $\mathrm{OPA}+\mathrm{A} 2+\mathrm{SF}(\mathrm{OPA}+\mathrm{A} 1+\mathrm{SF})$ experiment [Fig. 5a (5b)] and OPA forced by observed wind (Fig. 2c) is 0.45 (0.5), and that of MOM4 $+\mathrm{A} 3+\mathrm{SF}$ (Fig. 5c) with MOM4 forced by observed wind (Fig. $2 b$ ) is 0.48 . The 

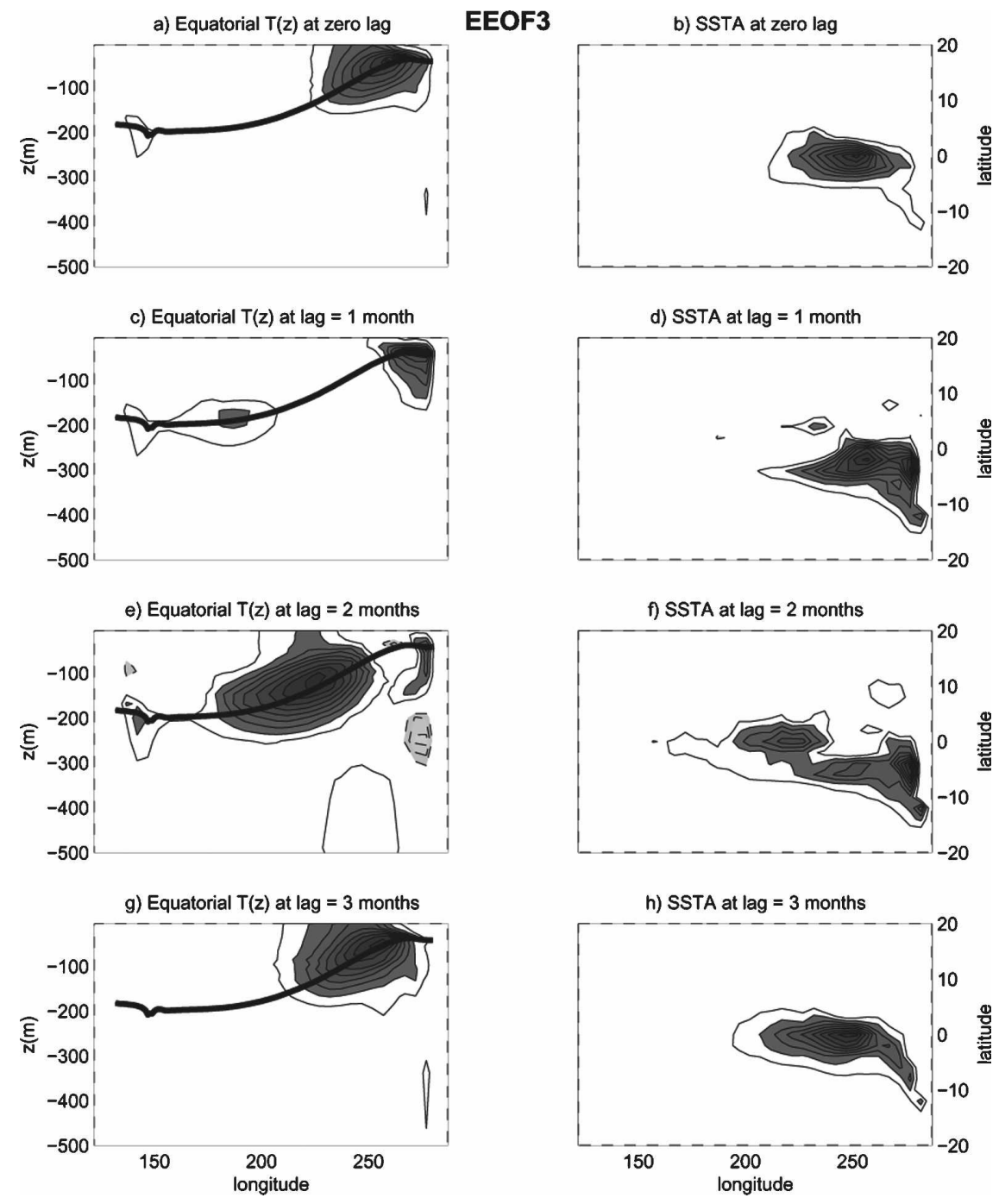

FIG. 4. As in Fig. 3 but for mode 3.

main reason for such a discrepancy is an accumulation of errors in the coupled hybrid models. To illustrate this point the model integration was repeated for the $\mathrm{OPA}+\mathrm{A} 1$ model but this time the initial conditions were redefined as 1 January of each year. The initial conditions are obtained from the ocean run forced by the observed zonal stress anomalies (Fig. 2c), which are shown again in Fig. 6a for comparison. Two experiments are presented. In the first experiment (Fig. 6b) the hybrid model was run without any externally imposed residual using the fields at the beginning of each year from Fig. 6a as the initial condition. In the second experiment $\tau_{n}$ was also prescribed as an external forcing. Reducing the accumulation of errors to one year yields the correct phase of the ENSO cycle most of the time. The addition of $\tau_{n}$ also helps by modifying the strength and improving the phase of the SST anomalies.
The zonally averaged correlation between Figs. 6a and $6 \mathrm{~b}$ is 0.57 , and that of Figs. $6 \mathrm{a}$ and $6 \mathrm{c}$ is 0.73 .

The response to the MJO and non-MJO components of the residual was similar for the three hybrid models. To illustrate the sensitivity to these components we show the response of the MOM4+A3 hybrid model in Fig. 7. The sum of the responses (Fig. 7c) is very similar to the response to the full noise. The zonally averaged correlation between Fig. $7 \mathrm{c}$ and the response to the full noise (Fig. 5c) is 0.93 . We therefore conclude that the response is highly linear. The same characteristics were observed for the other hybrid models. The high linearity in the response is also emphasized by looking at the response of the hybrid model to the intraseasonal MJO (Fig. 7d). In this experiment the MJO stress perturbations used in Fig. 7a were high passed for periods smaller than 90 days. Even though we allow for cou- 


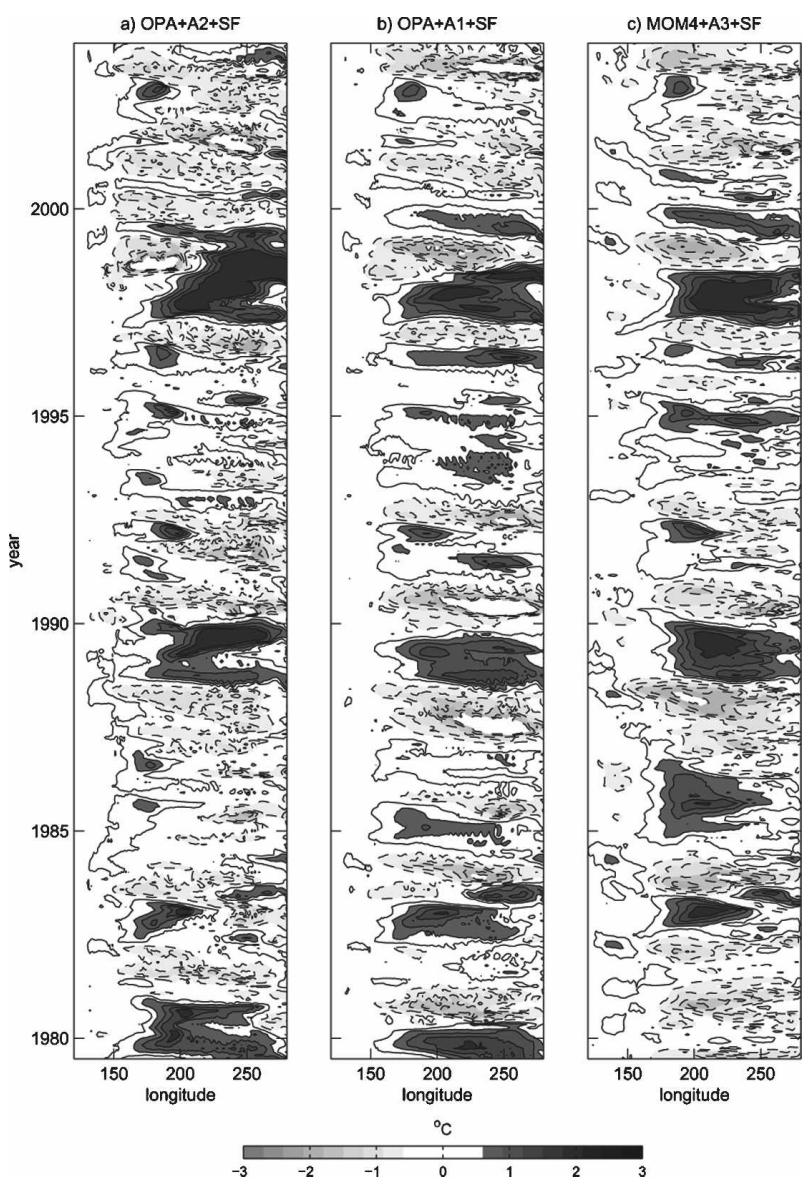

FIG. 5. Equatorial SST anomalies $\left(5^{\circ} \mathrm{N}-5^{\circ} \mathrm{S}\right.$ average) from the hybrid models forced by residual zonal wind stress (SF): (a) $\mathrm{OPA}+\mathrm{A} 2+\mathrm{SF}$, (b) $\mathrm{OPA}+\mathrm{A} 1+\mathrm{SF}$, and (c) $\mathrm{MOM} 4+\mathrm{A} 3+\mathrm{SF}$.

pling in this experiment, no interannual SST anomalies develop. The models are therefore responding to the low-frequency tail of the MJO, a result that was previously suggested by intermediate models (Roulston and Neelin 2000; Zavala-Garay et al. 2003; ZG05). Table 1 summarizes the amount of variance excited by different components of the residual wind in the OPA $+\mathrm{A} 1 \mathrm{hy}-$ brid model. Since the wind anomalies associated with the MJO typically explain less than $40 \%$ of the observed residual in the equatorial region and a large fraction of interannual variability can be excited by this forcing (see also Fig. 7), the MJO seems to be an important source of stochastic forcing in the hybrid models. The non-MJO can also lead to interannual variability in the hybrid models. Its variability, however, tends to be smaller than that induced by the MJO forcing.

To better illustrate the effect of the MJO on the coupled system we studied the response of the OPA + A1 hybrid model at the onset of the 1997-98 El Niño. Two types of MJO forcing are considered. In the
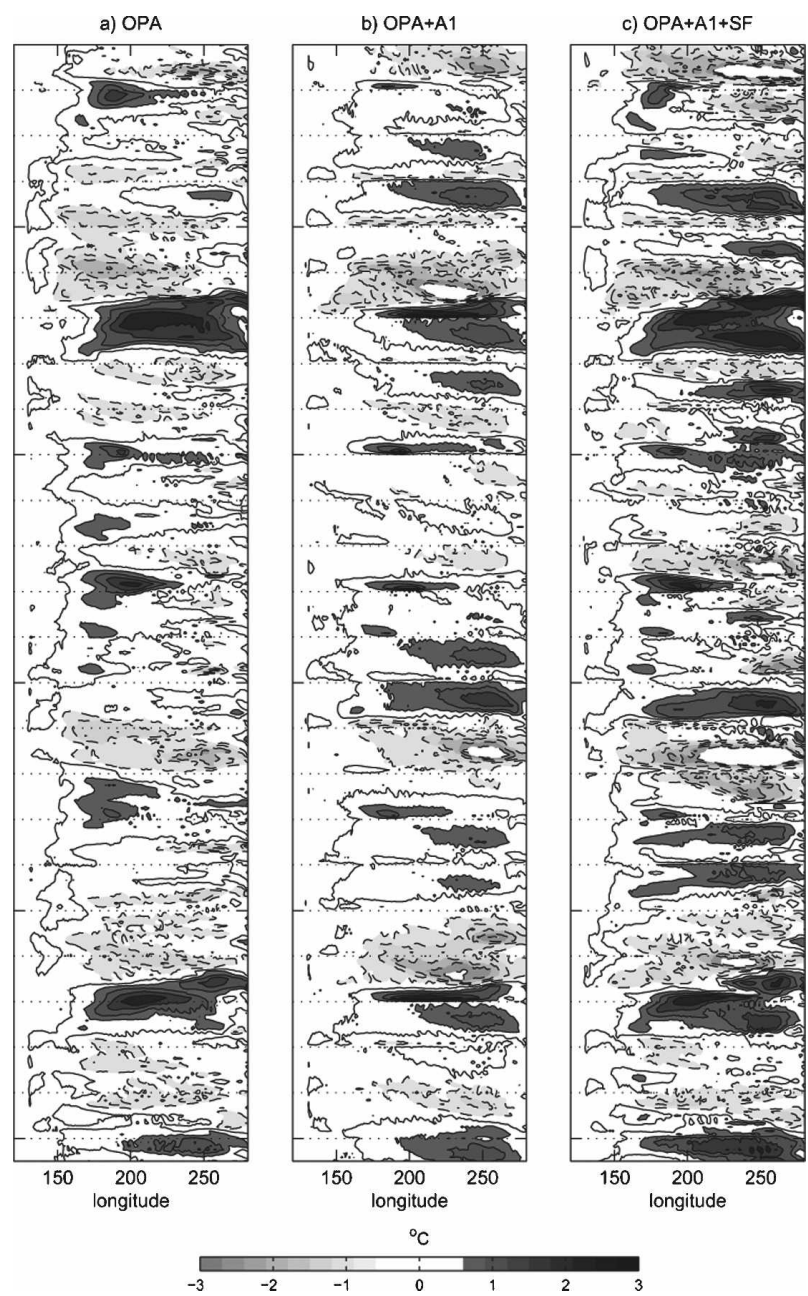

FIG. 6. SST anomaly modeled by (a) the OPA ocean model forced by observed zonal wind stress (as in Fig. 2c); (b) the $\mathrm{OPA}+\mathrm{A} 1$ hybrid model reinitialized on 1 Jan of each year (indicated by dotted lines) using the state of the integration shown in (a) as the initial condition; (c) the $\mathrm{OPA}+\mathrm{A} 1+\mathrm{SF}$.

first case the stress perturbations are based on the MJO estimate that includes its low-frequency tail. In the second case the stress perturbations are based on the highpassed MJO. This "intraseasonal MJO" was obtained by removing the resultant of two passes of a 91-day running mean. These two MJO estimates are shown in Fig. 8 for the period December 1996-January 1997. Three MJO events were observed during this period (Fig. 8a). The three events originate in the Indian Ocean, propagate eastward, and dissipate in the western/central Pacific. The intraseasonal MJO (Fig. 8b) is similar to the previous estimate. However, the filtering process has reduced the amplitude of the westerly wind anomalies and enhanced the easterly wind anomalies.

We now study the response of the OPA $+\mathrm{A} 1$ model to the two MJO estimates. To isolate the response of 

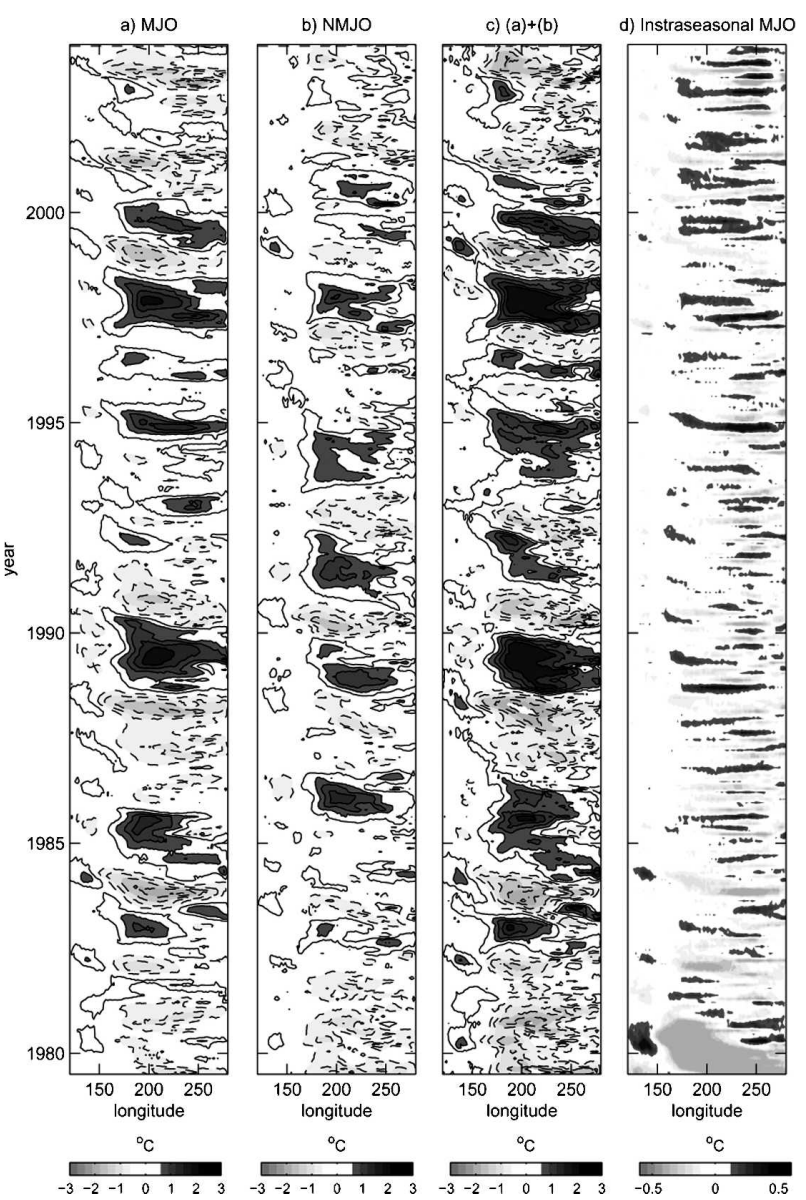

FIG. 7. Equatorial $\left(5^{\circ} \mathrm{N}-5^{\circ} \mathrm{S}\right.$ average) SSTA modeled by the MOM4+A3 hybrid model forced by (a) MJO stress perturbations, (b) nonMJO stress perturbations, and (d) intraseasonal MJO stress perturbations. (c) The sum of the MJO and nonMJO responses in (a) and (b).

the coupled model to the MJO stress perturbations alone, we eliminated any information contained in the initial conditions by forcing the OGCM with the climatological wind stress for 10 years. After this spinup period the OGCM reached equilibrium (i.e., no anomaly about the model annual cycle) and was coupled to the

TABLE 1. Zonal wind variance averaged over the domain $\left(5^{\circ} \mathrm{S}-\right.$ $5^{\circ} \mathrm{N}, 120^{\circ} \mathrm{E}-80^{\circ} \mathrm{W}$ ) for different components of the residual and amount of SST variance excited over the Niño-3.4 region $\left(5^{\circ} \mathrm{S}-\right.$ $5^{\circ} \mathrm{N}, 170^{\circ}-120^{\circ} \mathrm{W}$ ) in the OPA $+\mathrm{A} 1$ hybrid model: HF (LF) MJO refers to the high (low) frequency component of the MJO.

\begin{tabular}{lcc}
\hline \hline & $\begin{array}{c}\text { Zonal wind input } \\
\text { variance }\left(\mathrm{m}^{2} \mathrm{~s}^{-2}\right)\end{array}$ & $\begin{array}{c}\text { Variance (Niño-3.4 region) } \\
\text { in OPA }+\mathrm{A} 1\left({ }^{\circ} \mathrm{C}^{2}\right)\end{array}$ \\
\hline MJO & 1.1 & $0.52 \pm 0.08$ \\
LF MJO & 0.2 & $0.50 \pm 0.07$ \\
HF MJO & 1 & $0.06 \pm 0.02$ \\
nonMJO & 1.9 & $0.28 \pm 0.04$ \\
\hline
\end{tabular}

A1 atmospheric model. Since the model was tuned to be stable, no anomalies develop in the absence of any external forcing. We then integrated the hybrid model by forcing with the three MJO events during the period December 1996-June 1997 (Fig. 8). Figure 9 illustrates the response of the coupled model to the two MJO estimates. Vertical sections of the equatorial temperature anomaly are shown in order to compare with the dominant modes of ocean variability excited by the MJO described in section 4 and summarized in Figs. 3 and 4. It should be noted, however, that what is observed in Fig. 9 is the response of the coupled model and not the response of the OGCM alone as in Figs. 3 and 4.

We first consider the response of the hybrid model to the MJO estimate that includes its low-frequency tail. By January 1997 a positive subsurface anomaly in the western Pacific is observed (Fig. 9a) as a result of the westerly phase of the MJO event of December 1996 (Fig. 8a). This MJO-induced subsurface anomaly then propagates eastward as an equatorial Kelvin wave and warms the eastern Pacific during February/March. At the same time a second MJO event occurring in February/March forced a second subsurface warming in the western Pacific that propagates eastward as a Kelvin wave. The overall effect of these sequences of downwelling Kelvin waves is to persist the positive SST anomalies in the east so that westerly coupled zonal winds develop in the central Pacific and amplify the temperature anomalies as observed by the month of June in Fig. 9a. This is, therefore, an example of how the EEOF3 of Fig. 4 is amplified by the coupled system.

The coupled evolution of EEOF2 (Fig. 3) is exemplified by the hybrid model response to the intraseasonal MJO (Fig. 9b). The artificial introduction by the filtering process of an easterly phase produces cold subsurface anomalies in the model (March in Fig. 8b) that tend to cancel the warming trend produced by the December MJO event. This alternation of downwelling/ upwelling Kelvin waves substantially reduces the growth by coupled processes (see also Fig. 10b). That is, the coupled system needs to be perturbed long enough in the same direction for the positive feedback to develop. The low-frequency part of the MJO provides such sustained forcing. The hybrid models can respond very differently to very similar SF (the average pattern correlation between Fig. 8a and Fig. $8 \mathrm{~b}$ is 0.9 ), provided their low-frequency component is different (e.g., Fig. 9).

Figure 10a compares the Niño-3 indices (average temperature anomaly in the region $5^{\circ} \mathrm{S}-5^{\circ} \mathrm{N}, 150^{\circ}-$ $90^{\circ} \mathrm{W}$ ) in OPA forced by observed stress anomalies (Fig. 2c), OPA $+\mathrm{MJO}$ and $\mathrm{OPA}+\mathrm{A} 1+\mathrm{MJO}$, all starting 


\section{a) MJO}

Dec 01: 12 (2)

Dec 10: 2 \& a

Dec 20: 3 isus a

Jan 01: $\quad y^{2}$

Jan 10: 1.20

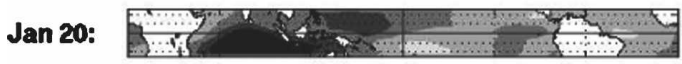

Feb 01: $f$ :

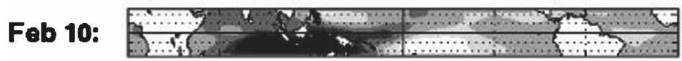

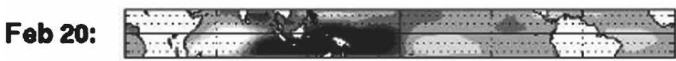

Mar 01: $: 34$.

Mar 10: $r_{0}=0$

Mar 20: 5 ins

Apr 01: $18 \times 48 x$

Apr 10: $\quad$ in

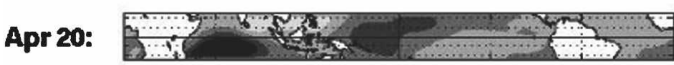

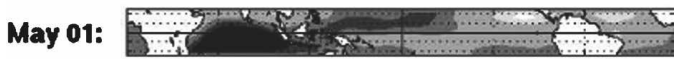

May 10:

May 20: $8 \%$ का

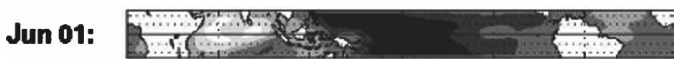

Jun 10: 1 .

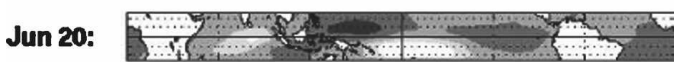

b) Intraseasonal MJO

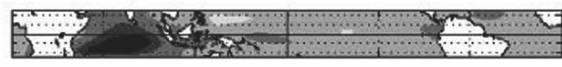

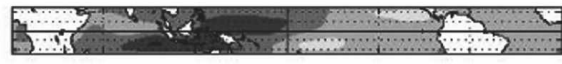

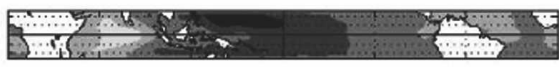

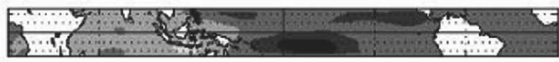

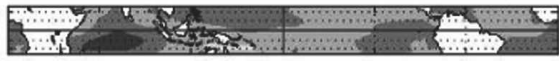

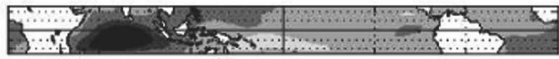

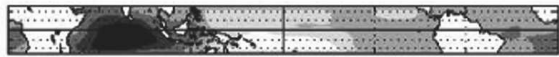

i.

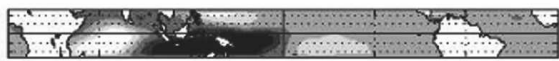

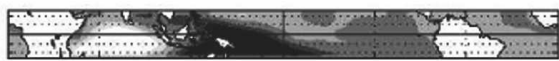

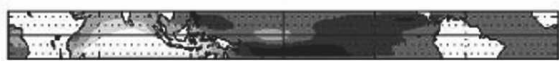

2 2 3
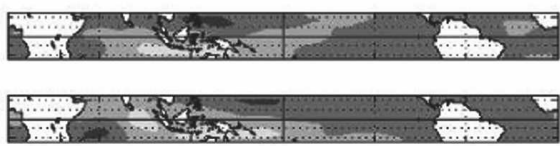

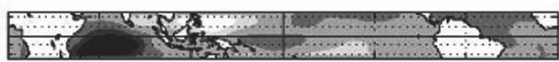
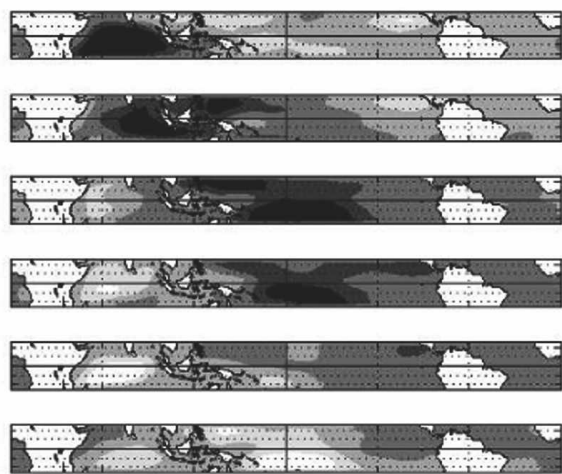

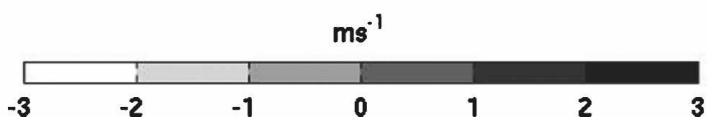

FIG. 8. Zonal wind anomalies associated with the MJO for the period December 1996-June 1997 (a) with and (b) without its low-frequency component. 

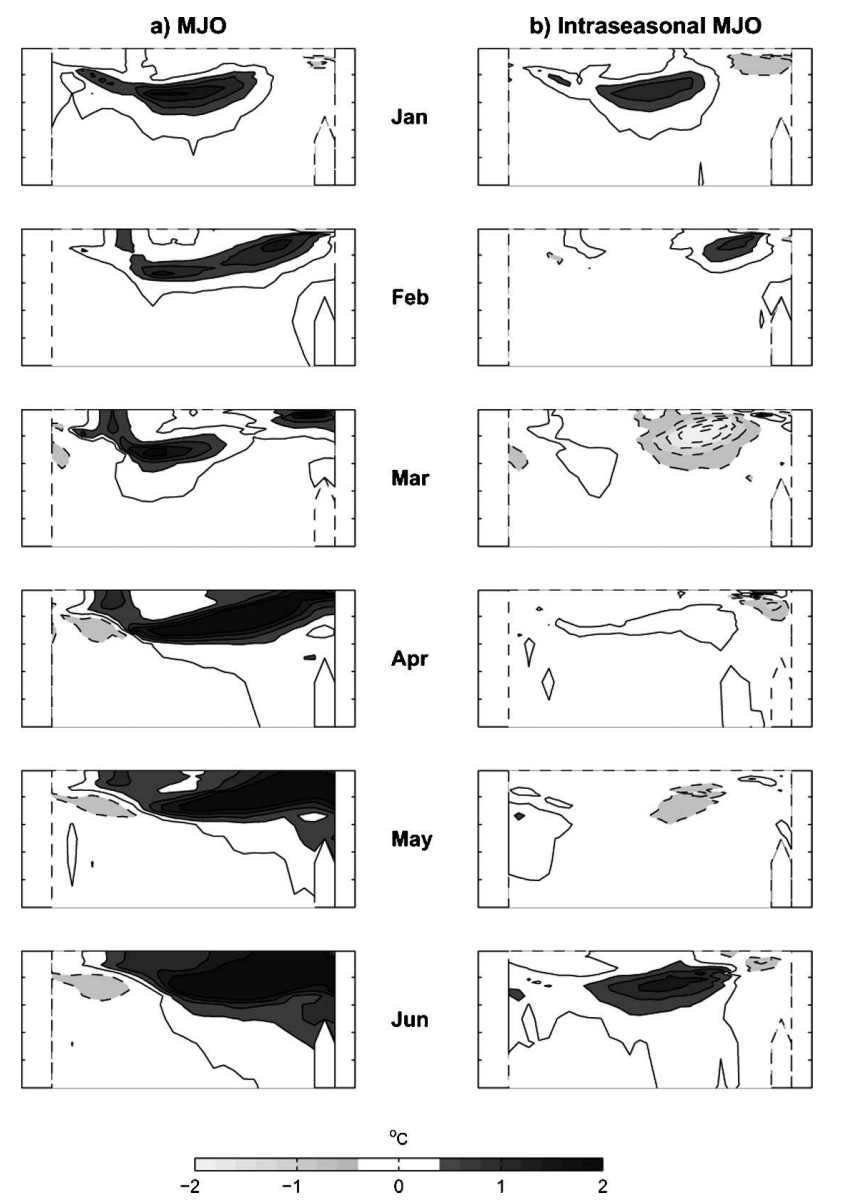

FIG. 9. Vertical cross sections of temperature anomalies from the OPA+A1 hybrid model forced by the MJO zonal stress over the period December 1996-June 1997 (a) with and (b) without its low-frequency component. The model integrations were initialized from an equilibrium state (i.e., null anomaly fields).

from an equilibrium state and the MJO added only for December 1996 to June 1997. This figure shows that the coupling with the atmosphere is instrumental in amplifying and persisting the MJO-induced perturbations. It is however the "cumulative" effect of the MJO on the ocean that is relevant in this regard. Because these integrations start from an equilibrium state, the variability in both the stand-alone OGCM and the hybrid model is excited only by the MJO. Figure $10 \mathrm{~b}$ is similar to Fig. 10a except the MJO forcing in OPA (without coupling) is high-pass filtered, and a nonequilibrium "best initial condition" obtained from the OPA forced by observed stress (see section 4 and Fig. 2c) was used in $\mathrm{OPA}+\mathrm{A} 1+\mathrm{MJO}$. The intraseasonal MJO does not produce large interannual variability. It is clear that most of the warming trend at the onset of the 1997-98 El Niño is forced by the MJO estimate (cf. dashed line in Fig. 10a). For comparison, the model prediction starting from this best initial condition but without the MJO added is also shown (dash-dotted line).

\section{Summary and discussion}

We studied the response of three hybrid ENSO models to observed estimates of unresolved variability, often referred to as stochastic forcing (SF). The great utility of such a simplification is that the SF is prescribed from observations and therefore is expected to add to the simulations an important piece of realism missing in the models. In addition, the use of hybrid models allow us to study with great detail the sensitivity of the ENSO coupled system to the different components of the SF, a task that would be very difficult using fully coupled GCMs.

The main effect of the SF on the ocean is to force equatorial Kelvin waves. The temperature anomalies associated with these waves typically originate in the subsurface, propagate eastward along the thermocline, and manifest themselves in the surface upon their arrival to the eastern Pacific, as observed (Zhang 2001). The results obtained with the three hybrid models are consistent with those found with an intermediate model (ZG05). We therefore conclude that a large impact on the coupled system by SF is not sensitive to model configurations.

While the wind anomalies associated with the MJO typically explain a small fraction of the SF, a large fraction of the interannual variability can be excited by this forcing. It should be noted, however, that other sources of SF can also produce interannual anomalies in the hybrid models (and in the intermediate model reported in ZG05). An extended EOF analysis of the response of the ocean to the uncoupled stress revealed that the observed SF is capable of forcing sequences of Kelvin waves of the same sign in the hybrid models. The overall effect of this sequence of waves is to maintain small SST perturbations in the eastern Pacific. When these small SST perturbations are allowed to interact with the atmospheric models large interannual anomalies develop.

An alternative view to this description is that the large-scale system resonates when mean westerlies are added to the west Pacific (Hendon et al. 2007). This effect is illustrated in Fig. 11 where the low-frequency tail (90-day running mean) of the MJO is shown for the period December 1996-June 1997 (Fig. 11a). The center of large activity situated in the eastern Indian Ocean during December 1996 and January 1997 slowly migrated eastward and northward through March-June 1997 in concert with the seasonal cycle of the MJO. When the OPA $+\mathrm{A} 1$ hybrid model is forced with this 

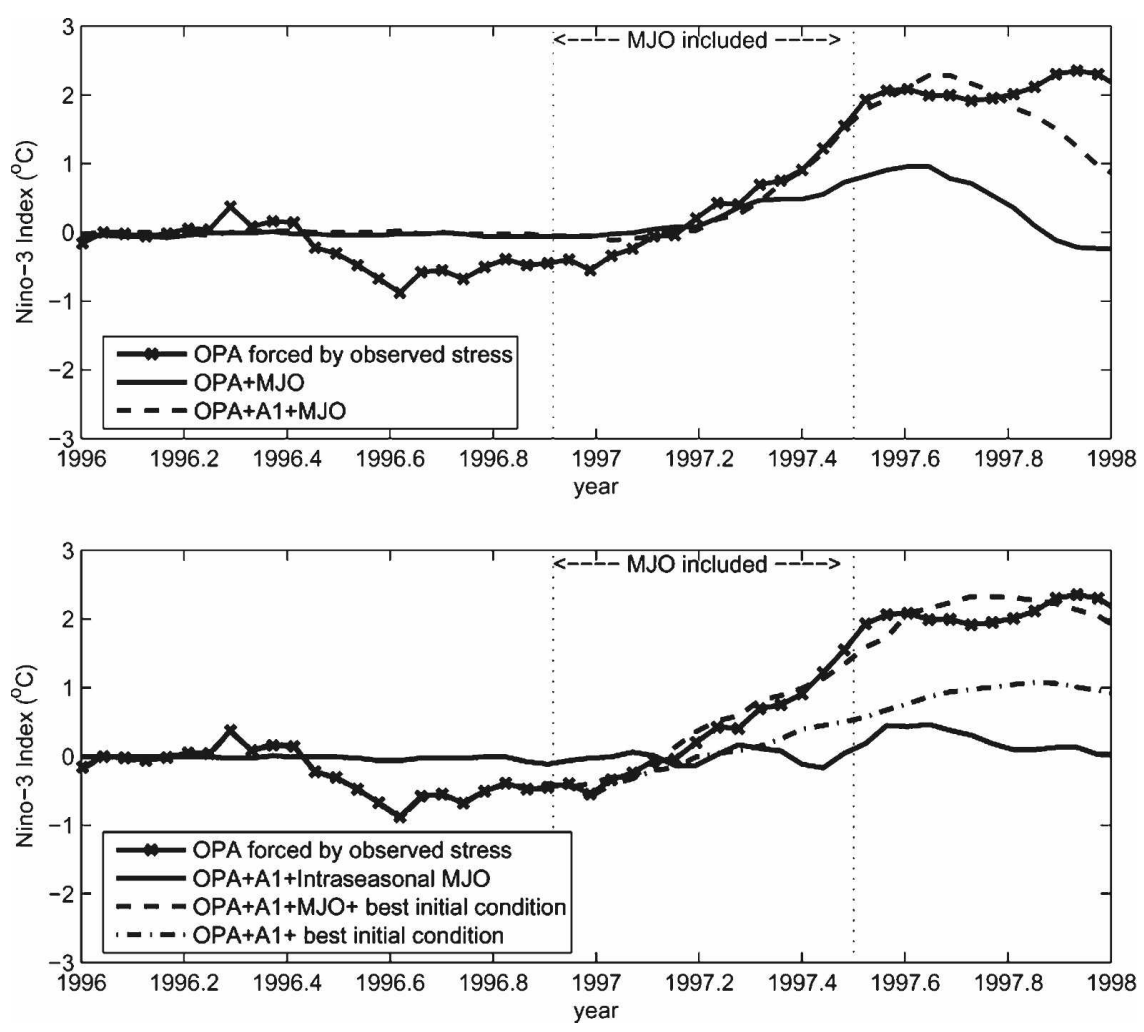

FIG. 10. Predicted Niño-3 indices for different simulations. (a) Solid-crossed line: OPA OGCM forced by NCEP2 zonal wind stress; solid line: OPA OGCM forced by the MJO component of the residual stress; dashed line: OPA+A1 hybrid model forced by the MJO estimate from December 1996 to June 1997. (b) Solid-crossed line: as in (a); solid line: $\mathrm{OPA}+\mathrm{A} 1$ hybrid model forced by the MJO as in (a), but with its low-frequency component removed; dashed line: as in (a), but the best possible initial condition, instead of an equilibrium state, was used; dash-dotted line: OPA + A1 initialized from best initial condition, but without the MJO estimate included.

low-frequency tail of the MJO shown in Fig. 11a, the vertical structure shown in Fig. $11 \mathrm{~b}$ is obtained. The response is similar to that obtained for the full MJO estimate (Fig. 9a), indicating that the ocean is a very effective low-pass filter. The net effect of such lowfrequency forcing is to warm the ocean along the thermocline during January and March. When these warm anomalies are upwelled by the seasonal winds to the surface, the coupled mechanism develops. One then wonders if this mechanism is independent of the intraseasonal activity of the MJO. To shed light on this question, we estimated the effect of the two components of the MJO (intraseasonal and its low frequency) on the ocean by projecting the MJO wind forcing onto the Kelvin wave characteristics, as in Zhang and Gottschalck (2002). This estimate, referred to as $K$, was found to closely correspond to thermocline anomalies in the OPA ocean model. To measure the effect of the intrasesonal MJO on the ocean, the seasonal activity of $K$ was defined as the running variance within a 3 -month running window. After removing its annual cycle the resulting time series, referred to as $\Delta \sigma_{K}\left(\tau_{\mathrm{MJO}}^{I}\right)$, represent interannual anomalies in seasonal variance of Kelvin waves forced by the intraseasonal MJO. To measure the effect of the low-frequency part of the MJO on the ocean, we computed $K$ using the 90-day running mean of the $\mathrm{MJO}$, referred to as $K\left(\tau_{\mathrm{MJO}}^{\mathrm{LF}}\right)$. We found that these two independent time series are significantly correlated (Fig. 12). That is, in years when the MJO tends to be more active it also produces a larger low-frequency contribution to the ocean, which can then resonate with the large-scale coupled system. This suggests that understanding the mechanisms by which the intraseasonal MJO interacts with the ocean to modulate its low-frequency content will help to better predict ENSO variability.

In fact, there are good reasons to believe that some of the variability included in our SF estimate is predictable. For example, Moore and Kleeman (1997) found that westerly wind bursts can be triggered by a weak 
a) low-frequency MJO

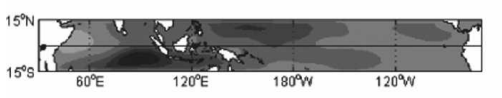

Dec

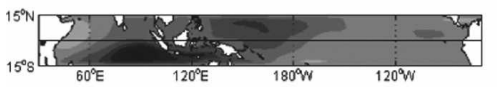

Jan

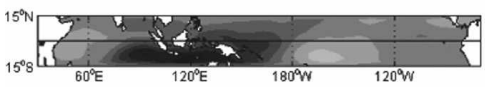

Feb

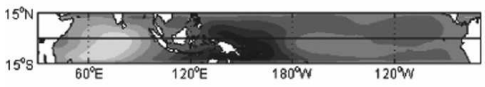

Mar

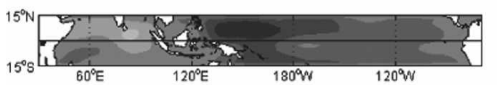

Apr
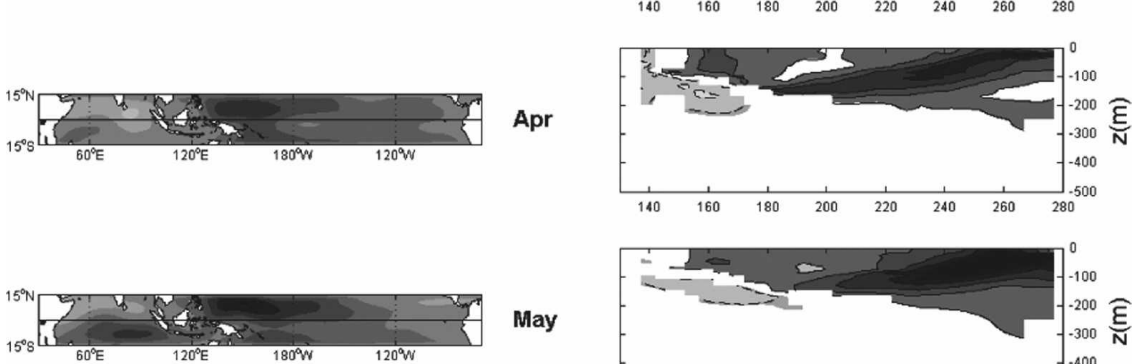

May

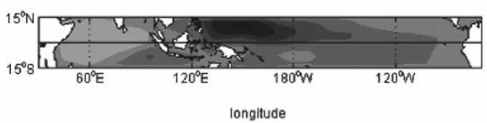

Jun

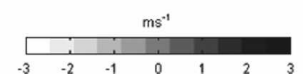

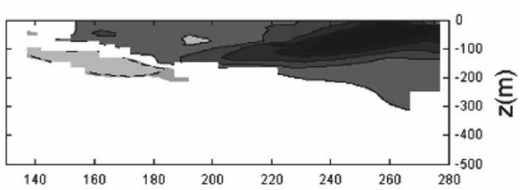

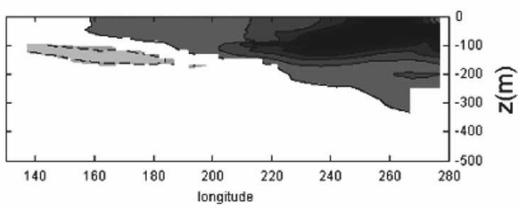

b) OPA+A1 Response
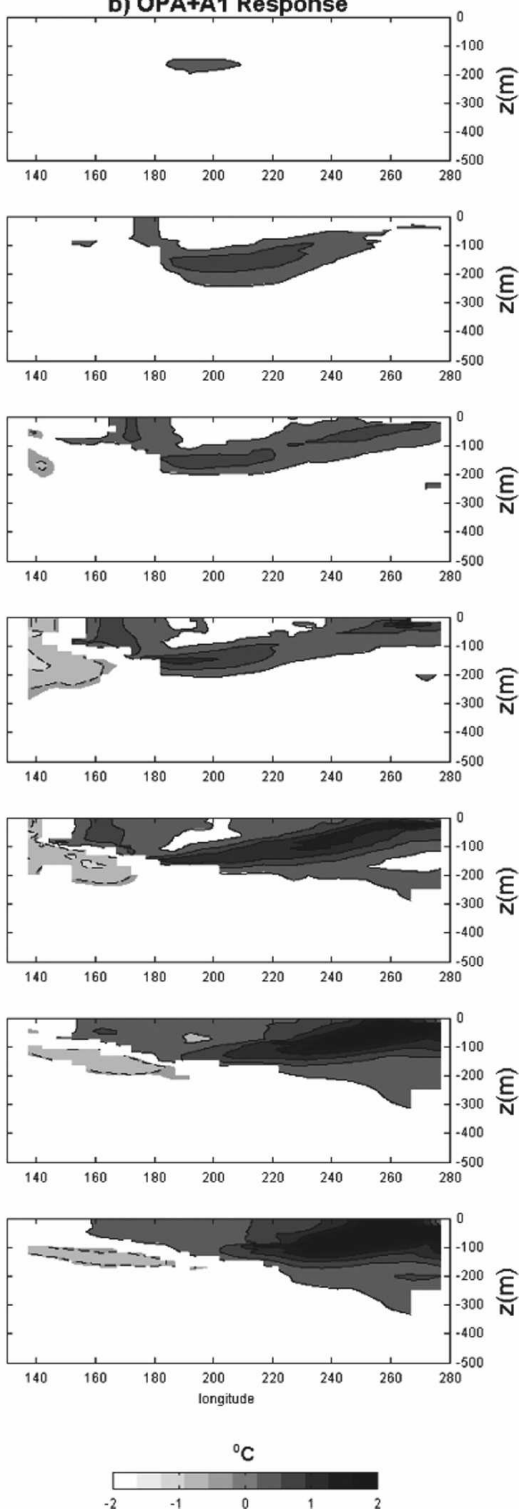

FIG. 11. (a) Zonal wind anomalies associated with the low-frequency tail of the MJO estimate (90-day running mean) for the period December 1996-June 1997. (b) Vertical sections of the temperature anomaly field produced by the OPA $+\mathrm{A} 1$ hybrid model initialized from climatology (zero anomaly) and forced by the wind anomalies shown in (a).

dipole in SST in the western Pacific, a finding that is supported by the observational study of Vecchi and Harrison (2000). Hendon et al. (2007) also identified enhanced MJO activity with anomalous MJO surface westerlies promoted by SST anomalies on the eastern edge of the Pacific warm pool. There is also observational evidence suggesting that ENSO itself may have a regulating effect on the generation of westerly wind bursts (WWBs) (Yu et al. 2003) pointing also to a partially deterministic process in the western Pacific.

It is also possible that the observed reddening of the
SF is due to SST outside the tropical Pacific (Roulston and Neelin 2000). For instance, Vimont et al. (2003) have identified a "seasonal footprinting mechanism" in which part of the summer variability in the tropical Pacific can be attributed to midlatitude SST anomalies forced by the overlying atmosphere during the previous winter. In addition, our understanding and modeling capabilities of the MJO have increased in the last decade (Zhang 2005), and all these processes are ignored in many coupled models; however, we have found that they are highly relevant for ENSO. 


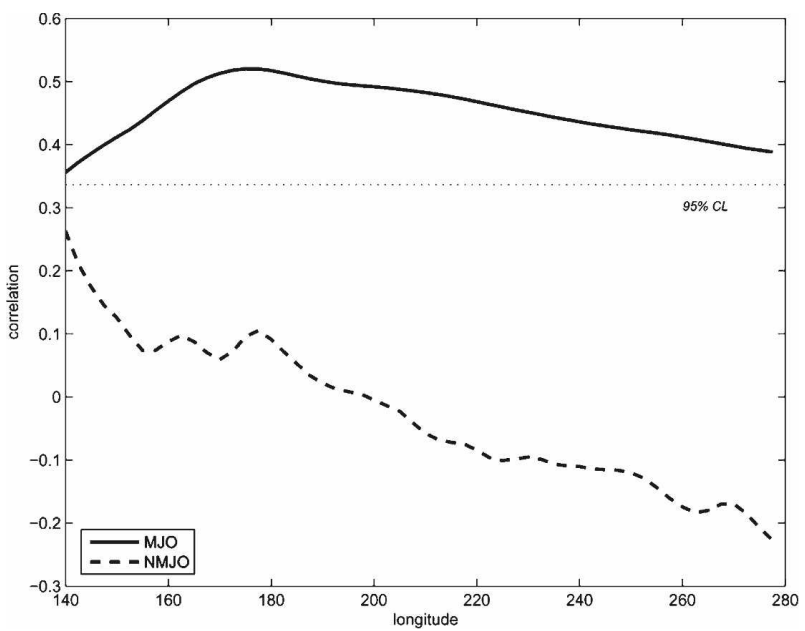

FIG. 12. Solid line: Correlation between interannual anomalies in seasonal variance of Kelvin waves forced by the intraseasonal $\left[\Delta \sigma_{K}\left(\tau_{\mathrm{M} \mathrm{JO}}^{I}\right)\right]$ and low-frequency $\left[K\left(\tau_{\mathrm{MJ} \mathrm{O}}^{\mathrm{LF}}\right)\right]$ components of the MJO. Dashed line: Same except for the nonMJO component of the residual zonal wind. The dotted line marks the $95 \%$ confidence level.

To illustrate to what extent knowledge of the unresolved variability could benefit ENSO forecasts, we evaluated the forecast skill of the model integrations shown in Fig. 6. Starting from the initial conditions provided by the OPA OGCM forced by observed zonal stress, two different coupled hindcasts were performed. In the first case, referred to as OPA + A1, the coupled model was run for one year starting in January and no residual was added during the forecast (Fig. 6b). In the second case, referred to as $\mathrm{OPA}+\mathrm{A} 1+\mathrm{SF}$, the same initial conditions as those in the previous case were used, but the stress perturbations due to the unresolved zonal wind were added during the integration process (Fig. 6c). In each case the Niño-3 index was computed and compared with that of the ocean stand-alone run forced by observed stress (Fig. 6a). Figure 13a shows the lag correlation between the observed Niño-3 index and the model predictions for the two cases. We rely on the problem of small sample size statistics and, therefore, the uncertainties associated with the correlations, indicated with vertical bars, are large. For a sample size equal to 25 , correlations above 0.5 are statistically significant at the $95 \%$ confidence level, and therefore the $\mathrm{OPA}+\mathrm{A} 1$ experiment exhibits a predictability of at most 4 months. In the OPA+A1+SF case, when the observed unresolved variability is added, lag correlations stay well above this level for the entire year. This improvement can also be appreciated by comparing the rms error of the two cases (Fig. 13b), as inclusion of the unresolved variability helps to reduce the rms error.

Oceanic stochastic forcing, such as the nonlinear rec-

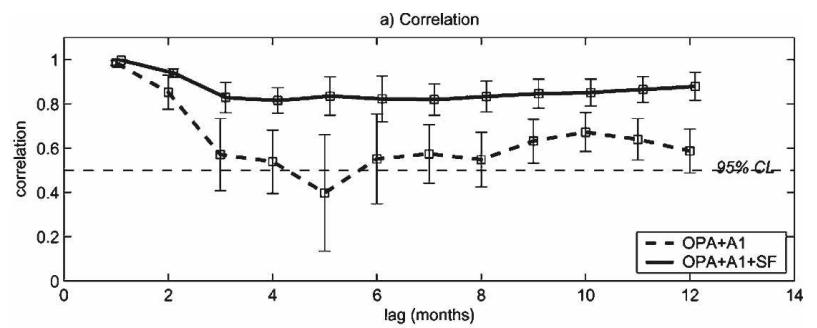

b) RMS

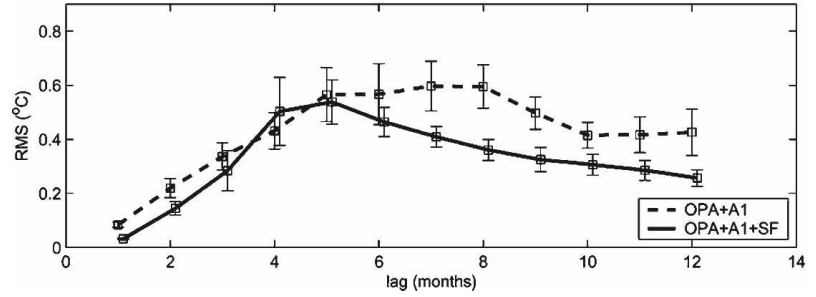

FIG. 13. (a) Correlation coefficients and (b) rms errors between Niño-3 indices from observations and the OPA + A 1 hybrid model with and without residual wind stress (SF), computed from an ensemble of 25 members initialized in January for the 1979-2003 period. The error bars of the correlation or rms are based on 100 bootstraps.

tification induced by tropical instability waves (TIWs), has been suggested as another source that contributes to interannual variability. In this mechanism the ocean produces interannual, large-scale, rectification patterns reflecting more or less activity due solely to the intrinsic nonlinearity of TIW. These TIW-induced SST changes can then force a significant increase of wind variability from intraseasonal to interannual time scales (Jochum et al. 2007). The OPA model used here can reproduce the main features associated with TIW. However, TIW activity in this model is more consistent with a limit cycle dynamical regime and therefore interannual variations in TIW activity mostly stem from variations of the surface wind (Vialard et al. 2003). Therefore, the nonlinear rectification mechanism reported by Jochum et al. (2007) is hardly present in our simulations, and no rectification from high frequency forcing to the interannual time scales (Kessler and Kleeman 2000) was found in the stable versions of the models.

A strong caveat of this study is that we have not considered heat flux anomalies induced by the intraseasonal variability. The MJO-related heat flux anomalies act to cool the western equatorial Pacific (Shinoda and Hendon 2002; Zhang and Anderson 2003), a process that can help to increase the east-west SST gradient promoting the growth of interannual anomalies in the hybrid models.

Acknowledgments. The valuable comments of two anonymous reviewers greatly improved the manuscript. 
The first and second authors are supported by a grant from the NOAA Office of Global Programs through the Cooperative Institute for Marine and Atmospheric Studies (CIMAS). The NCEP2 reanalysis data were obtained from the NOAA-CIRES Climate Diagnostics Center (CDC) Web page. The numerical experiments using the OPA model were performed at the Computational and Information Systems Laboratory of the National Center for Atmospheric Research.

\section{REFERENCES}

An, S. I., and B. Wang, 2000: Interdecadal change of the structure of the ENSO mode and its impact on the ENSO frequency. $J$. Climate, 13, 2044-2055.

Batstone, C., and H. H. Hendon, 2005: Stochastic variability associated with ENSO and the role of the MJO. J. Climate, 18 , 1773-1789.

Blanke, B., J. D. Neelin, and D. Gutzler, 1997: Estimating the effect of stochastic wind stress forcing on ENSO irregularity. J. Climate, 10, 1473-1486.

Bretherton, C. S., C. Smith, and J. M. Wallace, 1992: An intercomparison of methods for finding coupled patterns in climate data. J. Climate, 5, 541-560.

Chang, P., L. Ji, B. Wang, and T. Li, 1995: Interactions between the seasonal cycle and El Niño-Southern Oscillation in an intermediate coupled ocean-atmosphere model. J. Atmos. Sci., 52, 2353-2372.

Eckert, C., and M. Latif, 1997: Predictability of a stochastically forced hybrid coupled model of El Niño. J. Climate, 10, 14881504.

Fedorov, A. V., 2002: The response of the coupled tropical oceanatmosphere to westerly wind bursts. Quart. J. Roy. Meteor. Soc., 128, 1-23.

- and S. G. Philander, 2000: Is El Nino changing? Science, 228, 1997-2002.

— S. L. Harper, S. G. Philander, B. Winter, and A. Wittenberg, 2003: How predictable is El Niño? Bull. Amer. Meteor. Soc., 84, 911-919.

Griffies, S. M., M. J. Harrison, R. C. Pacanowsky, and A. Rosati, 2003: A technical guide to MOM4. GFDL Ocean Group Tech. Rep. 5, NOAA/GFDL, Princeton, NJ, 295 pp.

Harrison, D. E., and G. Vecchi, 1997: Westerly wind events in the tropical Pacific, 1986-1995. J. Climate, 10, 3131-3156.

Harrison, M., E. Galanti, A. Rosati, B. J. Soden, and E. Tziperman, 2002: An examination of air-sea flux products for ENSO simulation and prediction. Mon. Wea. Rev., 130, 723732.

Hartten, L. M., 1996: Synoptic settings of westerly wind bursts. $J$. Geophys. Res., 101, 16 997-17 019.

Hasselmann, K., 1976: Stochastic climate models. Part I: Theory. Tellus, 28, 473-485.

Hendon, H. H., M. Wheeler, and C. Zhang, 2007: Seasonal dependence of the MJO-ENSO relationship. J. Climate, 20, 531-543.

Jin, F.-F., J. D. Neelin, and M. Ghil, 1994: El Niño on the devil's staircase: Annual Subharmonic steps to chaos. Science, 264, $70-72$

_ L. Lin, A. Timmermann, and J. Zhao, 2007: Ensemble mean dynamics of the ENSO recharge oscillator under state- dependent stochastic forcing. Geophys. Res. Lett., 34, L03807, doi:10.1029/2006GL027372.

Jochum, M., C. Deser, and A. Philips, 2007: Tropical atmospheric variability forced by oceanic internal variability. J. Climate, 20, 765-771.

Kanamitsu, M., W. Ebisuzaki, J. Woollen, S.-K. Yang, J. J. Hnilo, M. Fiorino, and G. L. Potter, 2002: NCEP-DOE AMIP-II Reanalysis (R-2). Bull. Amer. Meteor. Soc., 83, 1631-1643.

Kessler, W. S., and R. Kleeman, 2000: Rectification of the Madden-Julian oscillation into the ENSO cycle. J. Climate, 13, 3560-3575.

Kleeman, R., 1991: A simple model of the atmospheric response to ENSO sea surface temperature anomalies. J. Atmos. Sci., 48, 3-18.

Lau, K. M., 1985: Elements of a stochastic dynamical theory of the long-term variability of the El Niño-Southern Oscillation. $J$. Atmos. Sci., 42, 1552-1558.

Leith, C. E., 1996: Stochastic models of chaotic systems. Physica $D$, 98, 481-491.

Lengaigne, M., J.-P. Boulanger, C. Menkes, G. Madec, and P. Delecluse, 2003: The March 1997 westerly wind event and the onset of the 1997/98 El Niño: Understanding the role of the atmospheric response. J. Climate, 16, 3330-3343.

Levitus, S., 1982: Climatological Atlas of the World Ocean. NOAA Prof. Paper 13, 173 pp. and 17 microfiche. , and T. P. Boyer, 1994: Temperature. Vol. 4, World Ocean Atlas 1994, NOAA Atlas NESDIS 4, 117 pp.

Madden, R. A., and P. Julian, 1971: Detection of a 40-50 day oscillation in the zonal wind in the tropical Pacific. J. Atmos. Sci., 28, 702-708.

, and R. H. Jones, 2001: A quantitative estimate of the effect of aliasing in climatological time series. J. Climate, 14, 39873993.

Madec, G., P. Delecluse, M. Imbard, and C. Levy, 1998: OPA 8.1 Ocean General Circulation Model reference manual. Institut Pierre-Simon Laplace des Sciences l'Environnement Global, LODYC, University Pierre et Marie Curie, Paris, France, 91 pp. [Available online at http://www.lodyc.jussieu.fr/opa.]

Maes, C., P. Delecluse, and G. Madec, 1998: Impact of westerly wind bursts on the warm pool of the TOGA-COARE domain in an OGCM. Climate Dyn., 14, 55-70.

Mantua, N. J., and D. S. Battisti, 1995: Aperiodic variability in the Zebiak-Cane coupled ocean-atmosphere model: Air-sea interactions in the western equatorial Pacific. J. Climate, 8, 2897-2927.

McPhaden, J. M., 1999: Genesis and evolution of the 1997-98 El Niño. Science, 283, 950-954.

, 2004: Evolution of the 2002/03 El Niño. Bull. Amer. Meteor. Soc., 85, 677-695.

Moore, A. M., and R. Kleeman, 1997: The singular vectors of a coupled ocean-atmosphere model of ENSO. Part I: Thermodynamics, energetics and error growth. Quart. J. Roy. Meteor. Soc., 123, 953-981.

_ and — 1999a: Stochastic forcing of ENSO by the intraseasonal oscillation. J. Climate, 12, 1199-1220. , and $1999 \mathrm{~b}$ : The non-normal nature of El Niño and intraseasonal variability. J. Climate, 12, 2965-2982. , J. Vialard, A. T. Weaver, D. L. T. Anderson, R. Kleeman, and J. R. Johnson, 2003: The role of air-sea interaction in controlling the optimal perturbations of low-frequency tropical coupled ocean-atmosphere modes. J. Climate, 16, 951968. 
- - and Coauthors, 2006: Optimal forcing patterns for coupled models of ENSO. J. Climate, 19, 4683-4699.

North, G. R., T. L. Bell, R. F. Cahalan, and F. J. Moeng, 1982: Sampling errors in the estimation of empirical orthogonal functions. Mon. Wea. Rev., 110, 699-706.

Penland, C., 1996: A stochastic model of Indo-Pacific sea surface temperature anomalies. Physica D, 98, 534-558.

- 2003: Noise out of chaos and why it won't go away. Bull. Amer. Meteor. Soc., 84, 921-925.

- and P. D. Sardeshmukh, 1995: The optimal growth of tropical sea surface temperature anomalies. J. Climate, 8, 19992024.

- M. Fluegel, and P. Chang, 2000: The identification of dynamical regimes in an intermediate coupled oceanatmosphere model. J. Climate, 13, 2105-2115.

Perez, C. L., A. M. Moore, J. Zavala-Garay, and R. Kleeman, 2005: A comparison of the influence of additive and multiplicative stochastic forcing on a coupled model of ENSO. $J$. Climate, 18, 5066-5085.

Reynolds, R. W., and T. M. Smith, 1994: Improved global sea surface temperature analyses using optimal interpolation. J. Climate, 7, 929-948.

Rosenblatt, M., 1956: Remarks on some nonparametric estimates of a density function. Ann. Math. Stat., 27, 832-837.

Roulston, M. S., and J. D. Neelin, 2000: The response of an ENSO model to climate noise, weather noise, and intraseasonal forcing. Geophys. Res. Lett., 27, 3723-3726.

Shinoda, T., and H. H. Hendon, 2002: Rectified wind forcing and latent heat flux produced by the Madden-Julian oscillation. $J$. Climate, 15, 3500-3508.

Silverman, B. W., 1986: Density Estimation for Statistics and Data Analysis. Vol. 26, Monographs on Statistics and Applied Probability, Chapman and Hall, 175 pp.

Thompson, C. J., and D. S. Battisti, 2000: A linear stochastic dynamical model of ENSO. Part I: Model development. J. Climate, 13, 2818-2832.

Tziperman, E., L. Stone, M. A. Cane, and H. Jarosh, 1994: El Niño chaos: Overlapping of resonances between the seasonal cycle and the Pacific ocean-atmosphere oscillator. Science, 264, 72-74.

van Oldenborgh, G., 2000: What caused the onset of the 1997/98 El Niño? Mon. Wea. Rev., 128, 2601-2607.

Vecchi, G. A., and D. E. Harrison, 2000: Tropical Pacific sea surface temperature anomalies, El Niño, and equatorial westerly wind events. J. Climate, 13, 1814-1830.

_ - A. T. Wittenberg, and A. Rosati, 2006: Reassessing the role of stochastic forcing in the 1997-98 El Niño. Geophys. Res. Lett., 33, L01706, doi:10.1029/2005GL024738.

Vialard, J., C. Menkes, J.-P. Boulanger, P. Delecluse, E. Guilyardi, M. McPhaden, and G. Madec, 2001: A model study of oceanic mechanisms affecting equatorial Pacific SST during the 1997-98 El Niño. J. Phys. Oceanogr., 31, 1649-1675.

,-- D. L. T. Anderson, and M. Balmaseda, 2003: Sensitivity of Pacific Ocean tropical instability waves to initial conditions. J. Phys. Oceanogr., 33, 105-121.

Vimont, D. J., J. M. Wallace, and D. S. Battisti, 2003: The sea- sonal footprinting mechanism in the Pacific: Implications for ENSO. J. Climate, 16, 2668-2675.

Weare, B. C., and J. S. Nasstrom, 1982: Examples of extended empirical orthogonal function analyses. Mon. Wea. Rev., 110, 481-485.

Wheeler, M. C., and H. H. Hendon, 2004: An all season real-time multivariate MJO index: Development of an index for monitoring and prediction. Mon. Wea. Rev., 132, 1917-1932.

Wilks, D. S., 1995: Statistical Methods in the Atmospheric Sciences. Academic Press, 467 pp.

Wittenberg, A. T., 2002: ENSO response to altered climates. Ph.D. thesis, Princeton University, 475 pp. , 2004: Extended wind stress analyses for ENSO. J. Climate, 17, 2526-2540.

Yu, L., and M. Rienecker, 1998: Evidence of an extratropical atmospheric influence during the onset of the 1997-98 El Niño. Geophys. Res. Lett., 25, 3537-3540.

_ R. A. Weller, and W. T. Liu, 2003: Case analysis of a role of ENSO in regulating the generation of westerly wind bursts in the western equatorial Pacific. J. Geophys. Res., 108, 3128, doi:10.1029/2002JC001498.

Zavala-Garay, J., A. M. Moore, C. L. Perez, and R. Kleeman, 2003: The response of a coupled model of ENSO to observed estimates of stochastic forcing. J. Climate, 16, 2827-2842.

,-- , and R. Kleeman, 2004: Influence of stochastic forcing on ENSO prediction. J. Geophys. Res., 109, C11007, doi:10.1029/2004JC002406.

_, C. Zhang, A. M. Moore, and R. Kleeman, 2005: The linear response of ENSO to the Madden-Julian Oscillation. J. Climate, 18, 2441-2459.

Zhang, C., 1996: Atmospheric intraseasonal variability at the surface in the western Pacific Ocean. J. Atmos. Sci., 53, 739-785.

_ 2001: Intraseasonal perturbations in sea surface temperatures of the equatorial eastern Pacific and their association with the Madden-Julian oscillation. J. Climate, 14, 13091322 .

2005: The Madden-Julian Oscillation. Rev. Geophys., 43, RG2003, doi:10.1029/2004RG000158.

— ponents of the intraseasonal oscillation in tropical convection. J. Atmos. Sci., 54, 741-752.

— Madden-Julian oscillation in the equatorial Pacific. J. Climate, 15, 2429-2445.

—, and S. P. Anderson, 2003: Sensitivity of intraseasonal perturbations in SST to the structure of the MJO. J. Atmos. Sci., 60, 2196-2207.

—, M. Dong, S. Gualdi, H. H. Hendon, E. D. Maloney, A. Marshall, K. R. Sperber, and W. Wang, 2006: Simulations of the Madden-Julian Oscillation in four pairs of coupled and uncoupled global models. Climate Dyn., 27, 573-592.

Zhang, S., M. J. Harrison, A. T. Wittenberg, A. Rosati, J. L. Anderson, and V. Balaji, 2005: Initialization of an ENSO forecast system using a parallelized ensemble filter. Mon. Wea. Rev., 133, 3176-3201. 